This article has been scanned by iThenticat No plagiarism detected

Volume 3, Issue 3, June 2021

p. $90-103$

THEORIZING AND ROOTING IN THE JURISPRUDENCE OF MINORITIES IN ISLAMIC ECONOMIC THOUGHT

http://dx.doi.org/10.47832/2757-5403.3-3.10

Mahdi Ali ABDALLAH 1

\begin{abstract}
:
This research deals with a juristic view of the Islamic economic insight on the existence of Muslims in the non-Muslim countries in the West and how to handle their problem of housing and providing them with houses through dealing with usurious banks. Moreover, it is about helping them to have a well-off living by creating an Islamic market or Muslim merchants. The morals, principles and thought of Islam can be introduced to the world of non-Muslims. So, the mechanism of creating the market and merchants has been tackled. Besides, the issue of when Muslim have the right to deal with such banks has also been addressed throughout making use of the rules of jurisprudence. May Allah help and guide us. That is why the research is titled (Theorizing and rooting in the jurisprudence of minorities in Islamic economic thought)
\end{abstract}

Key words: Islamic Economic; Theorizing; Rooting.

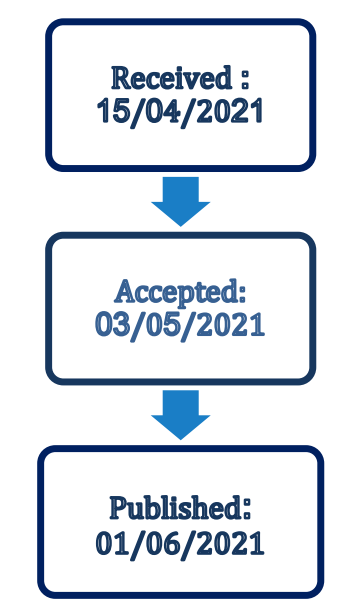

التنظير والتأصيل في فقة الأقليات المسلمة في فكر الاقتصاد الإسلامي

\footnotetext{
${ }^{1}$ Dr. , Telafer University, Iraq, dr.mahdi.abdallah@uotelafer.equ.iq, https://orcid.org/0000-0002-7162-8095
} 


\title{
2
}

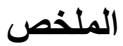

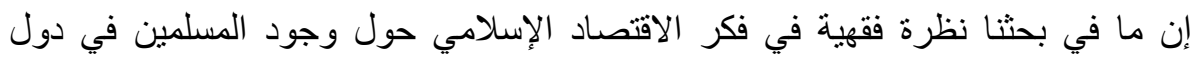

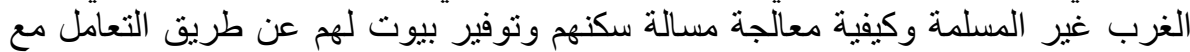

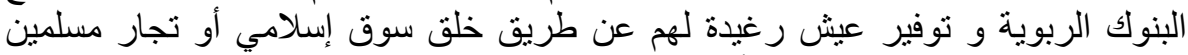

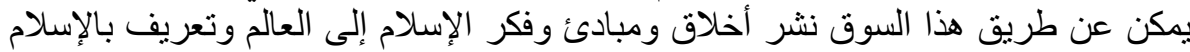

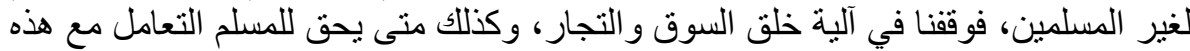

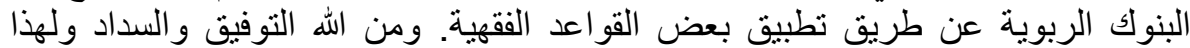

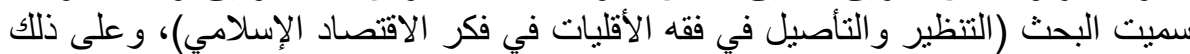

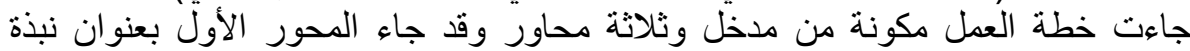

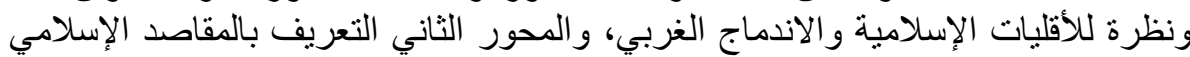

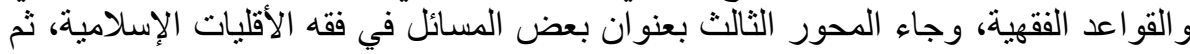

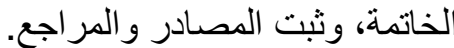
الكلمات المفتاحية: التنظير، التأصيل، الاقتصاد الإسلامي.
\end{abstract}

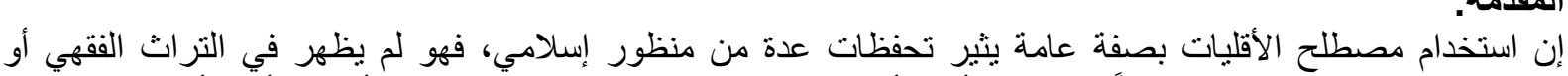

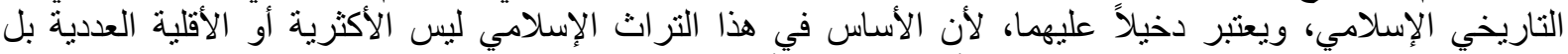

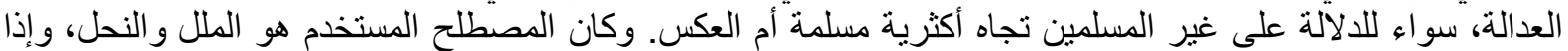

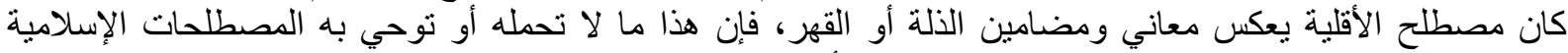

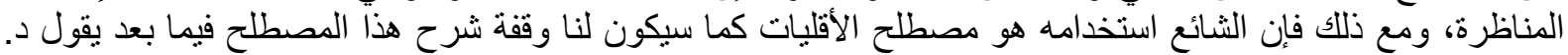

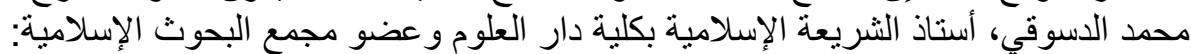

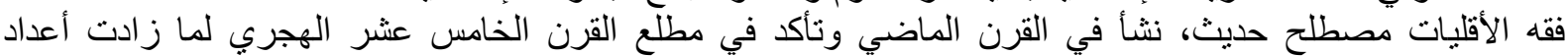

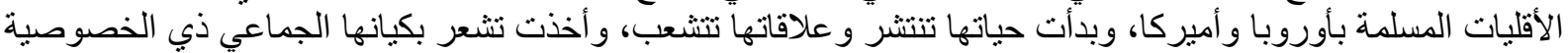

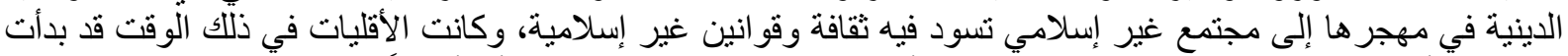

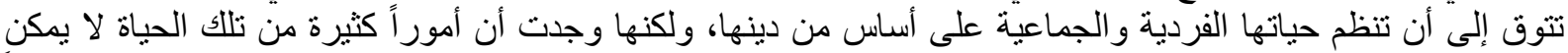

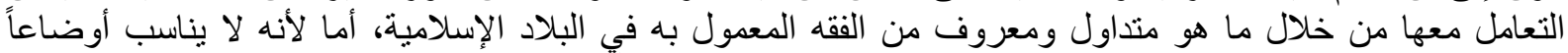

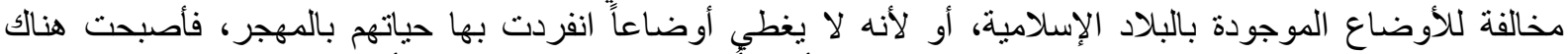

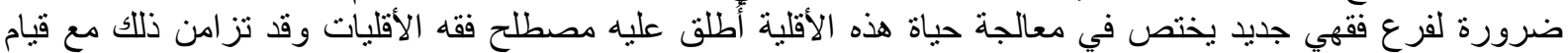
الهيئات الإسلامية المهتمة بأوضاع تللك الجاليات المسلمة والمجتمعات المسلمة في بلاد الغرب.

أحكام خاصة

ويؤكد الدسوفي أن فقه الأقليات لا يعني إنشاء فقه خارج الفقه الإسلامي و أدلته المعروفة، و إنما يعني أن هذه الفئة لها

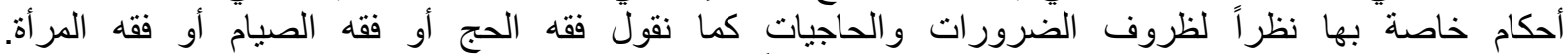

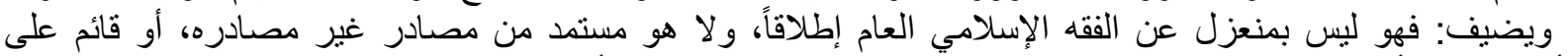

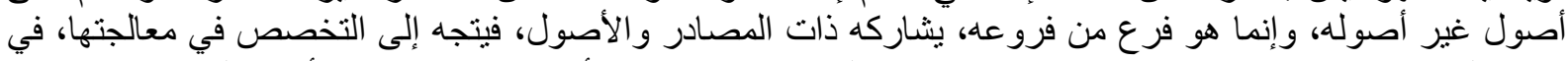

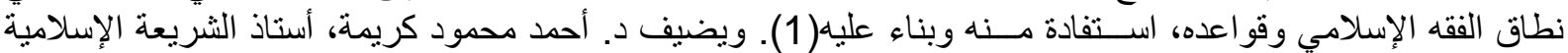

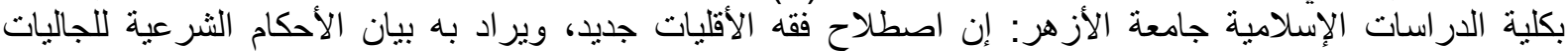

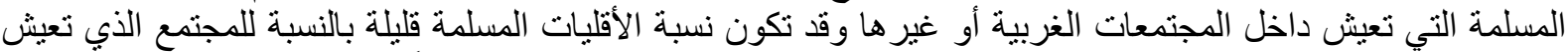

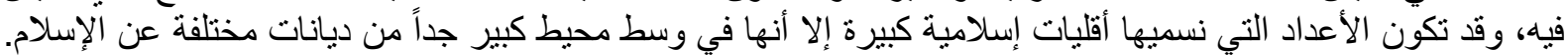

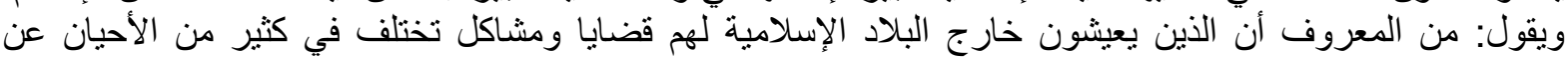

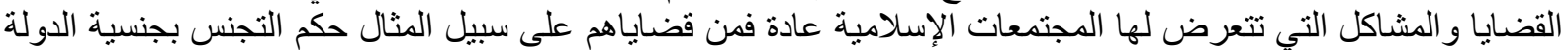

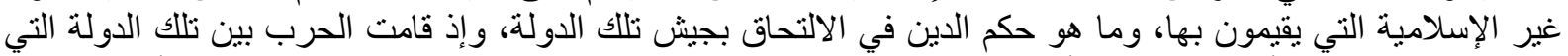

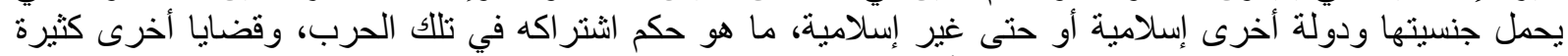

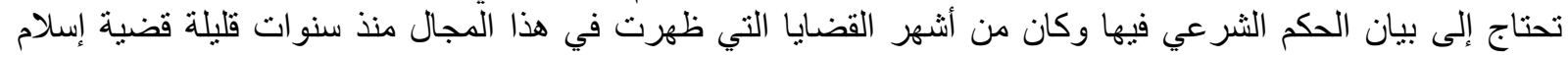




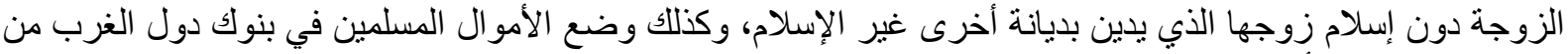

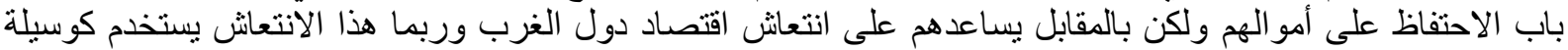

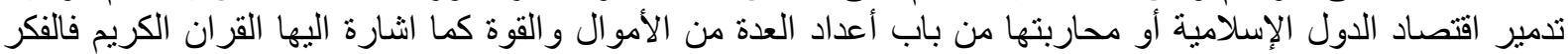

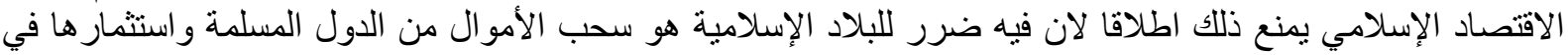

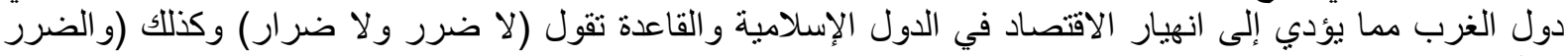

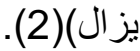
فالهدف من فقه الأقليات هو ان يعين الأقليات الإسلامية على اداء الواجبات العات المختلفة: الدينية و الثقافية و الاقتصادية و المالية

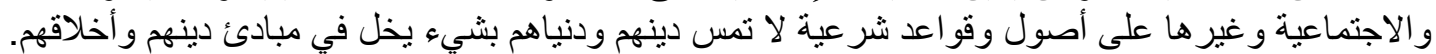

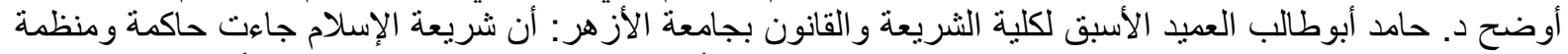

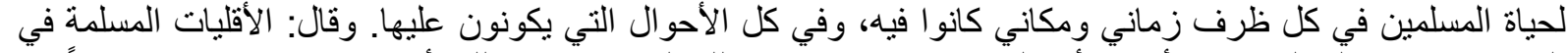

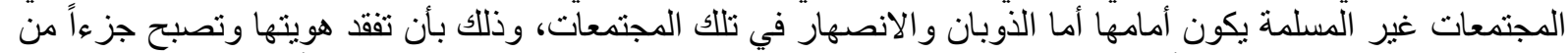

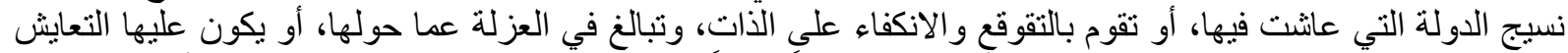

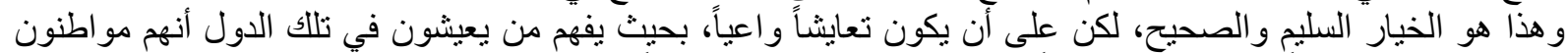

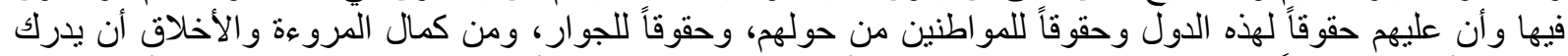

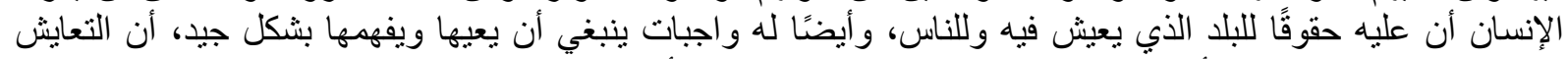

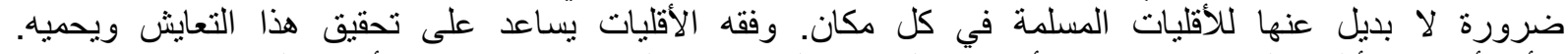

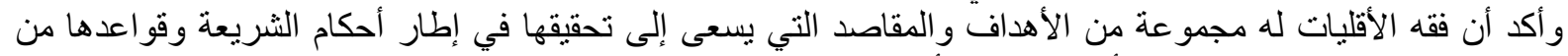

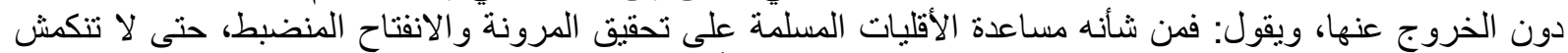

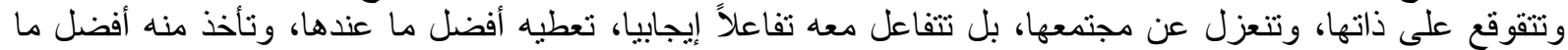

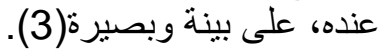

\section{المدول الأول}

نبذة ونظرة للأقليات السلامية والاندماج الغربي

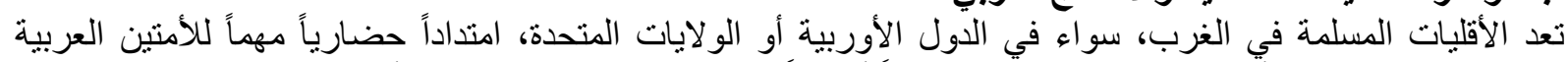

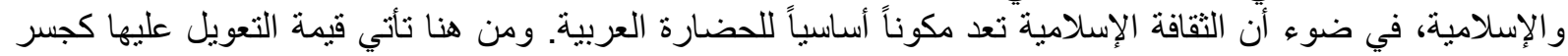

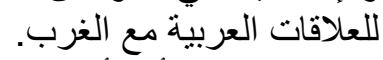

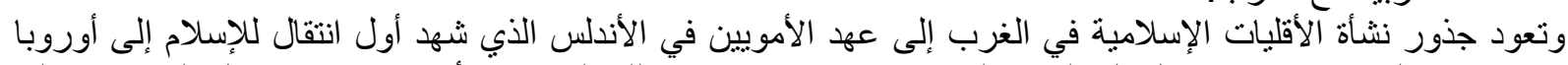

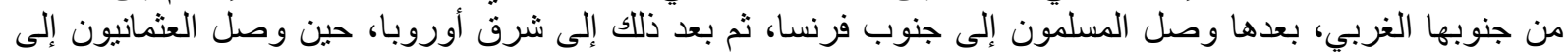

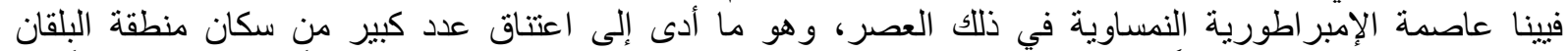

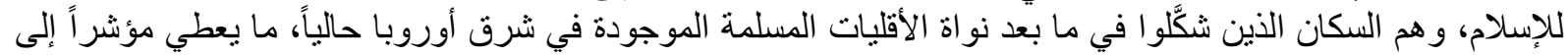

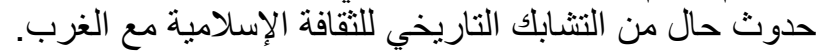

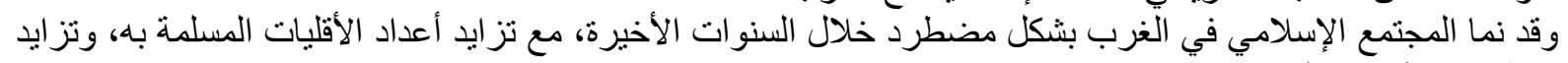

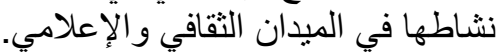

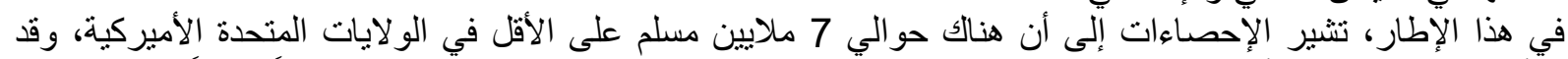

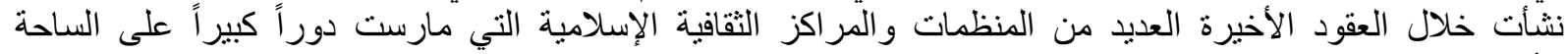
الأميركية.

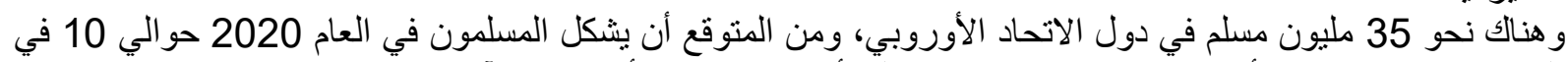

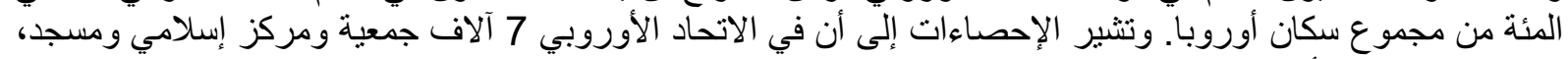

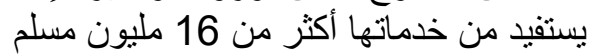

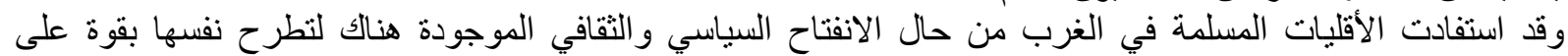

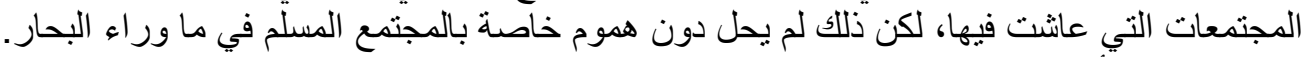

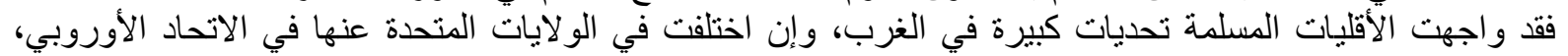

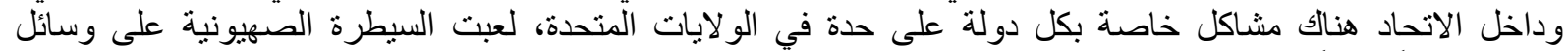

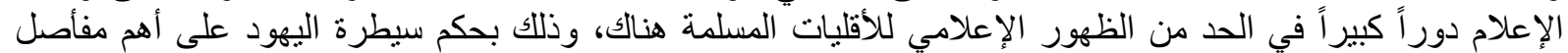
الاقتصاد الأميركي 
أما الوضع في الاتحاد الأوروبي، فإنه يختلف من دولة إلى أخرى، كما ذكرنا سلفا، ففي إيطاليا التي وصل عدد المسلمين

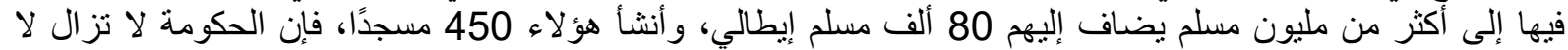

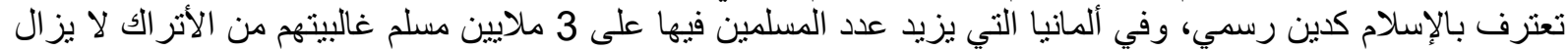

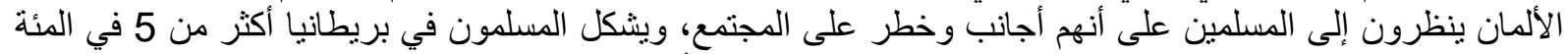

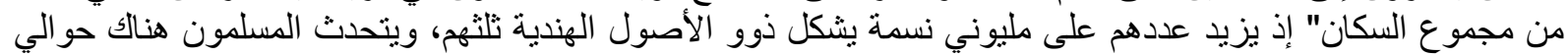

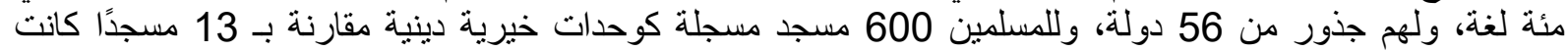
موجودة العام 1963، كذللك يوجد 560 دولئه 1400 جمعية إسلامية. ويبدو الوضع في بريطانيا أفضل من غير ونيره، إذ أن القانون البريطاني ينظر إلى إلى الجماعات العرقية المختلفة نظرة إيجابية،

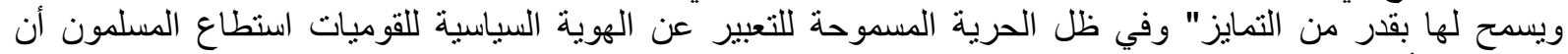

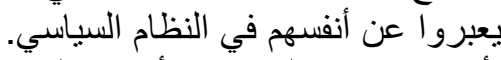
أما في فرنسا التي تضم أكبر جالية إسلامية على أراضيها الفيها إذ يبلغ عدد المسلمين فيها حوالي ستة ملايين لديهم 1300

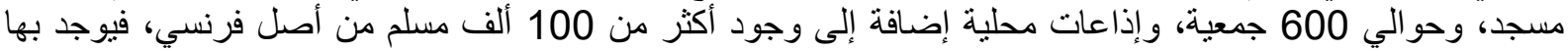

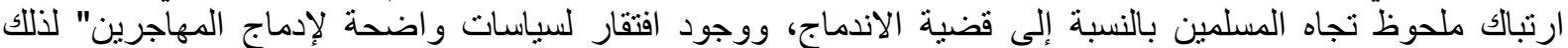

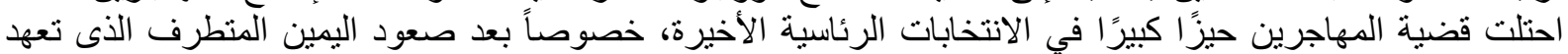

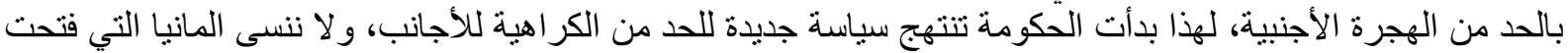

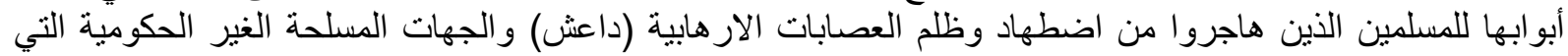

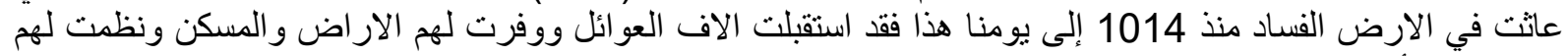

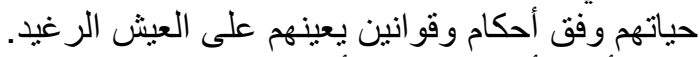

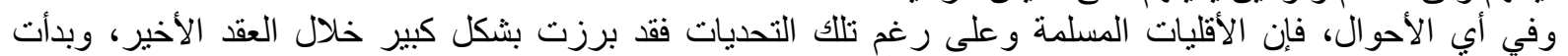

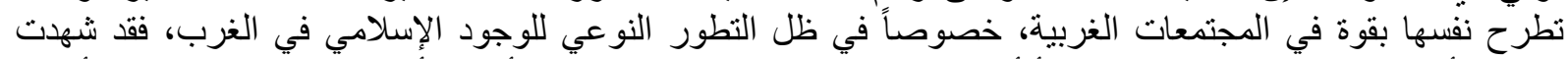

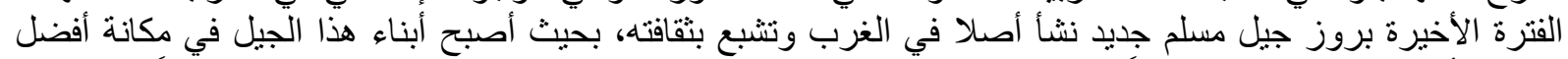

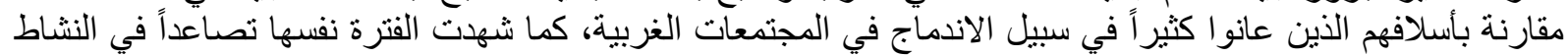

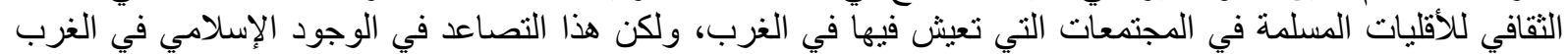

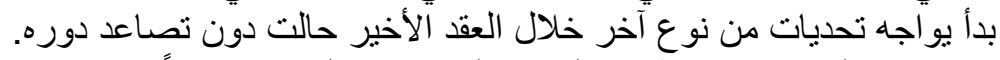

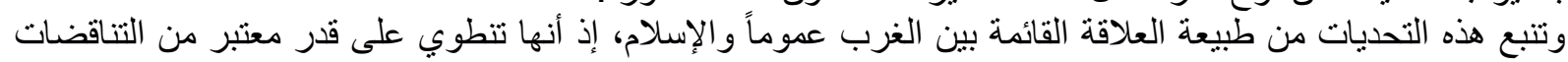

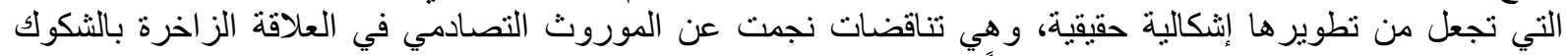

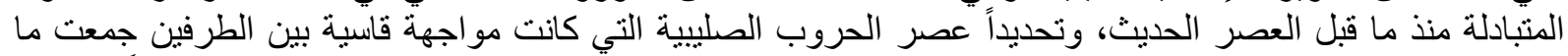

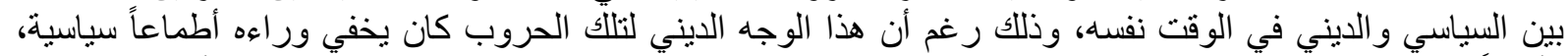

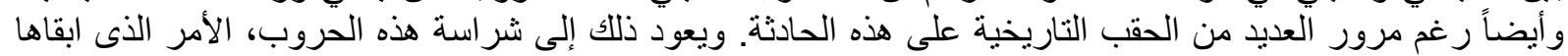

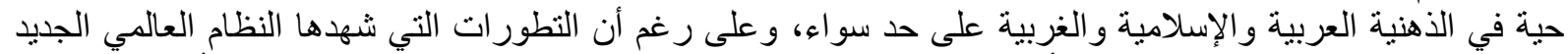

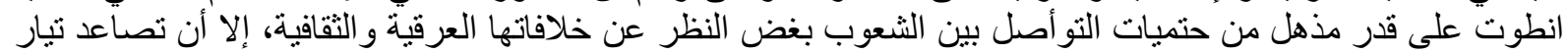
العولمة جاء ليغذي فكرة الصدام بين الإسلام والغرب، خاصة مع الانتشار الهائل الذي حقتنه فكرة الصدام بين

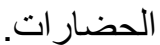
وفي الواقع فإن ثمة عاملاً أساسياً أدى إلى وضع الإسلام والعولمة كل على طرف نقام نقيض في مواجهة الآخر ، فالعولمة

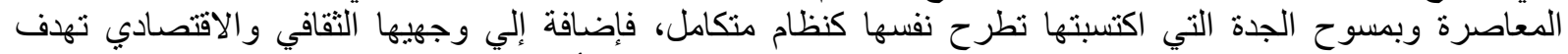

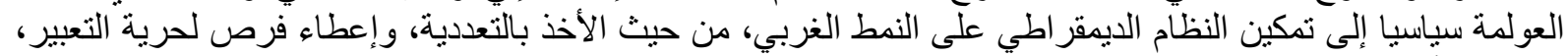

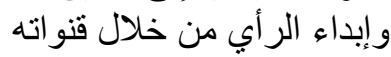

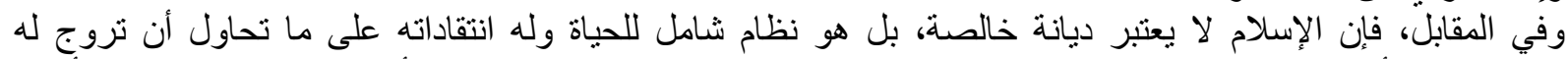

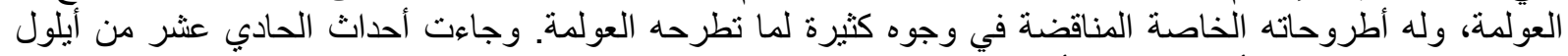

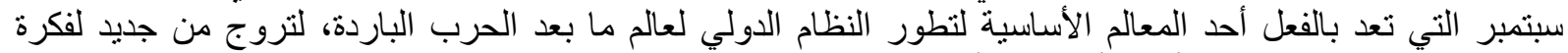

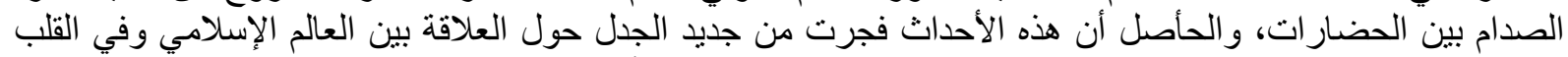

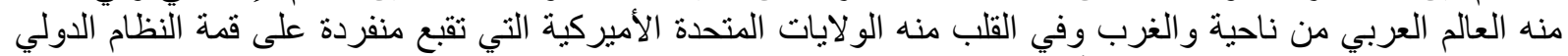

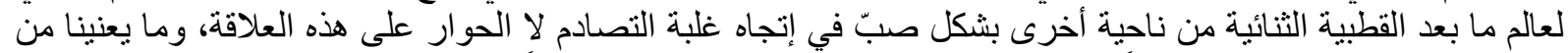

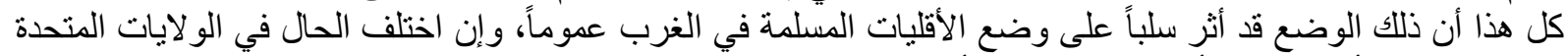

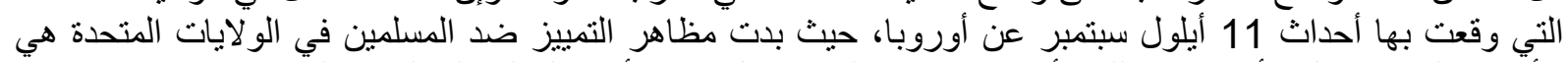

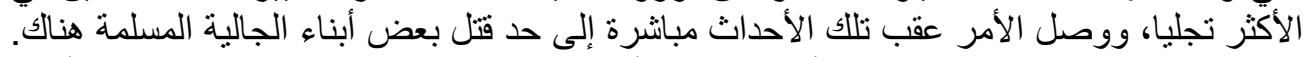

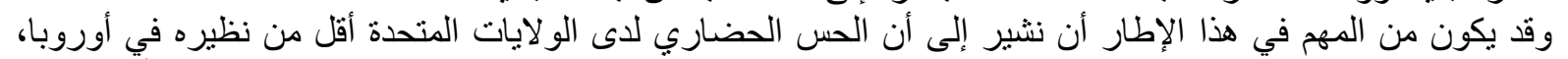

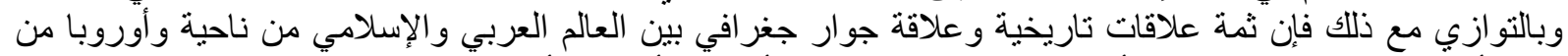

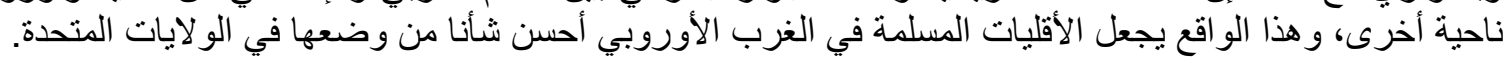




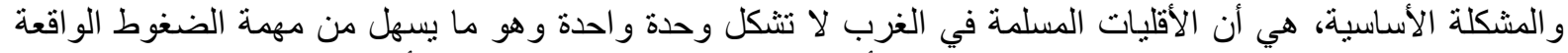

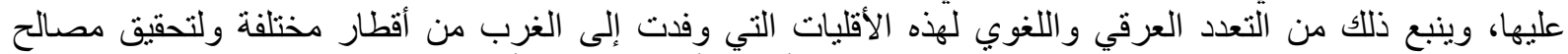

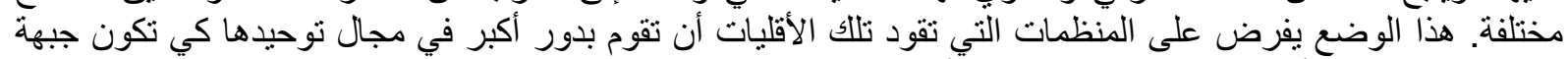

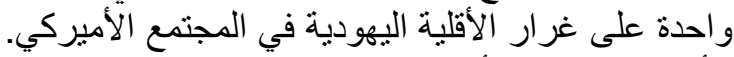

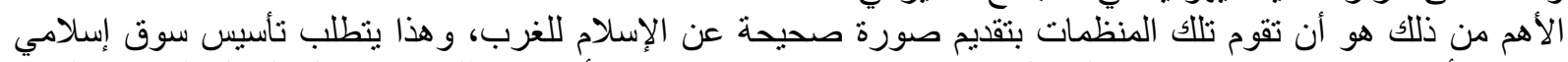

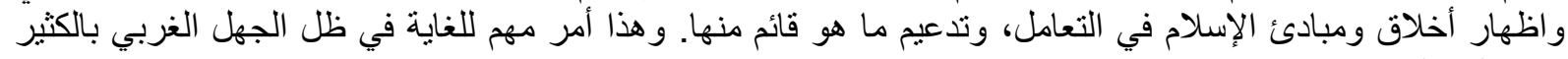

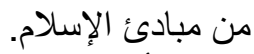

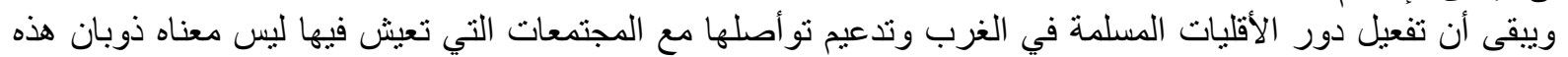

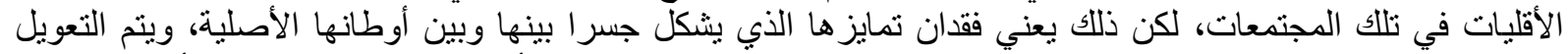

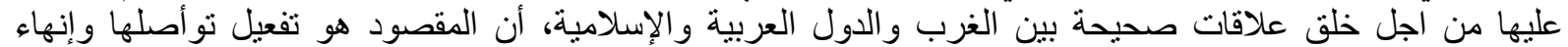

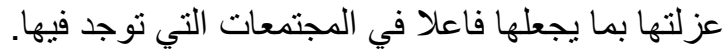
و هذا يتطلب تثبيت عقيدة الو لاء وتعزيز الانتماء من قبل تلألك الأقليات إلى العالم الإسلامي، ولا يكون ذللك إلا بتعلم العقيدة

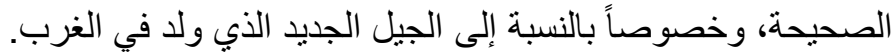

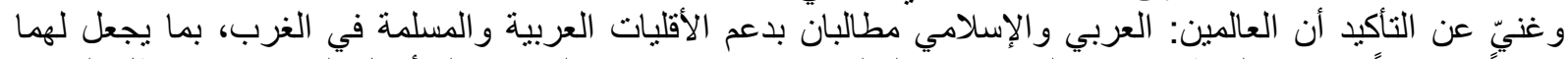

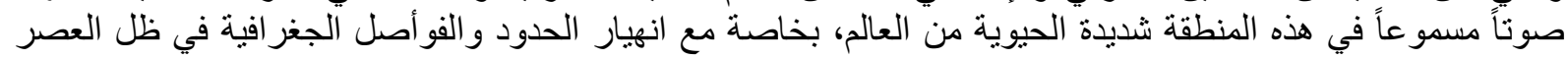

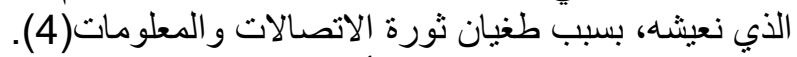

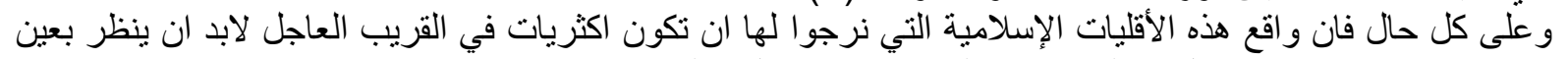

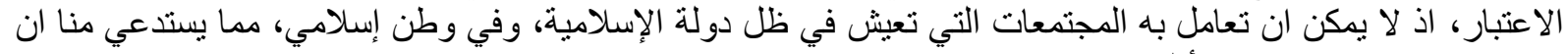

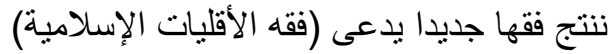

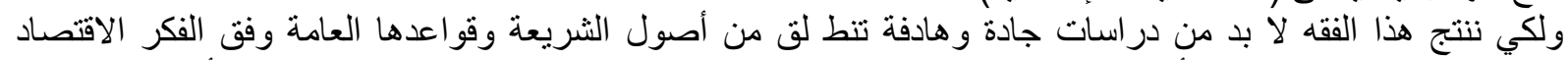

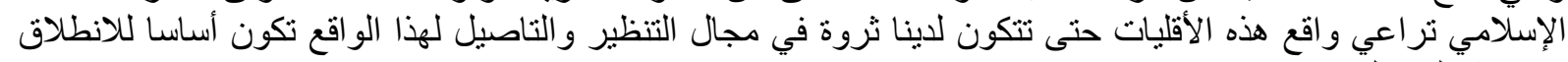

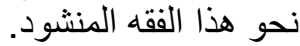

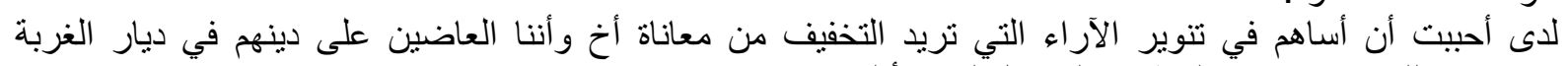

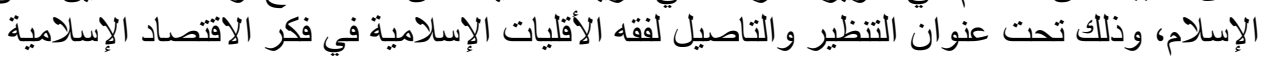

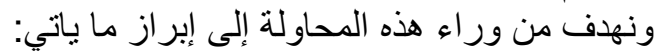

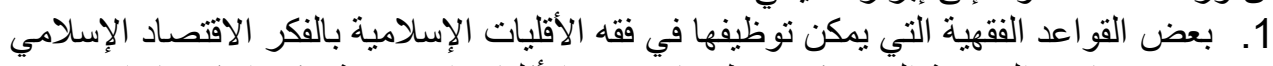

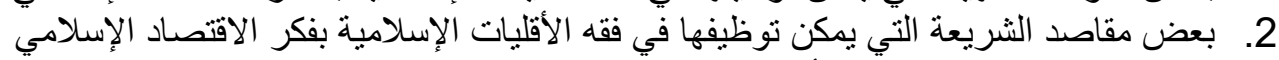

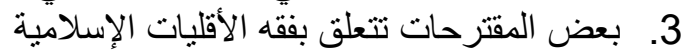
وقبل الخوض في فقه الأقليات علينا تعريف بعض الألئ المصطلحات في صدد موضو عنا لغة واصطلاحا.

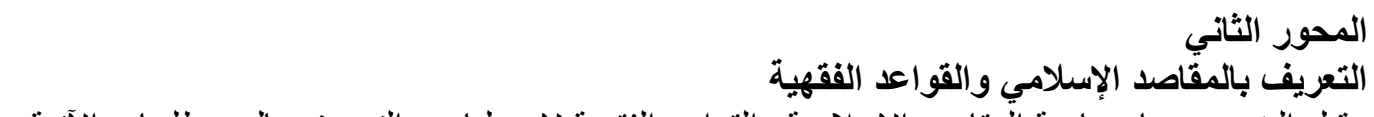

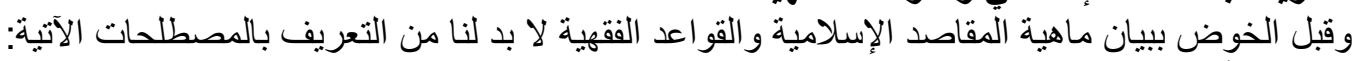
تعريف الأقليات

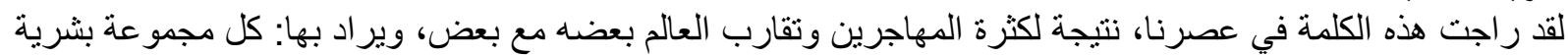

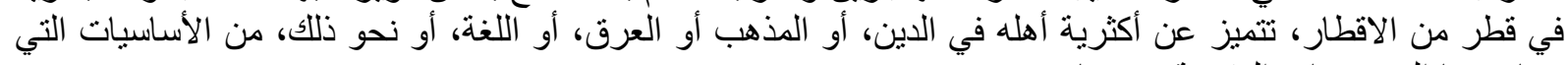

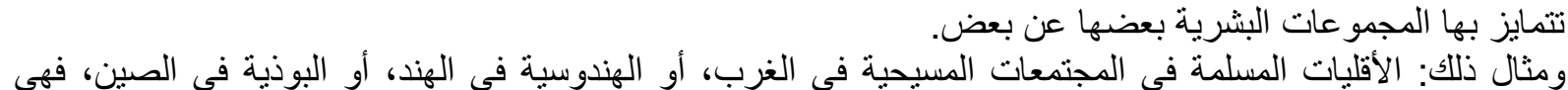

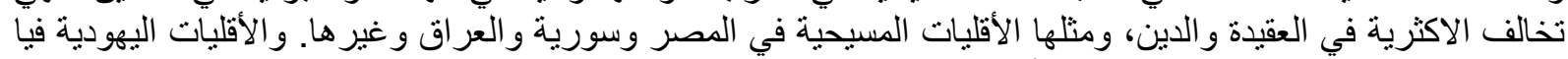

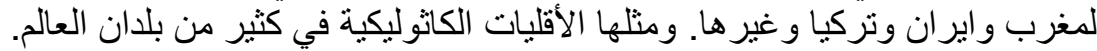

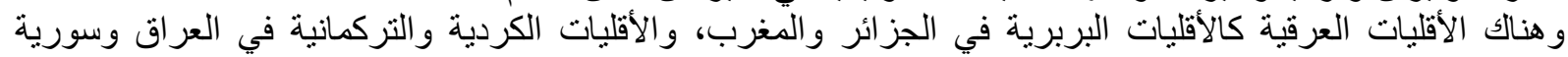

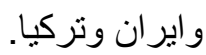
و وناك الأقليات اللغوية، مثل الأقليات الناطقة بالفرنسية في كندا (مونتربال وما حولها).

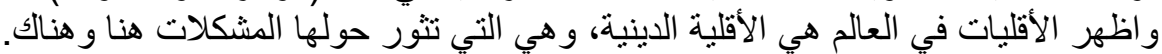

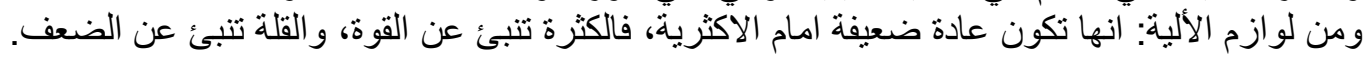


و القران يحدثنا عن الكثرة في معرض الامتنان و التذكير بالنعمة، وذللك على لسان شعيب _ عليه السلام _ حين قال لقومه

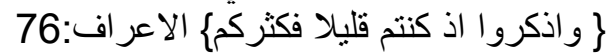

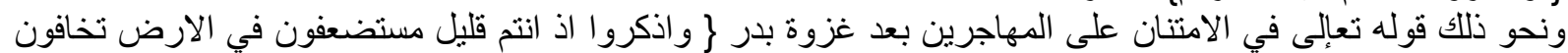

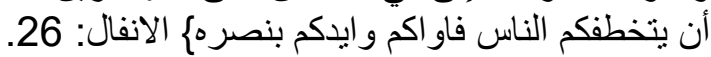
وقال عمرو بن كلثوم مفاخر البكثرة قومانه:

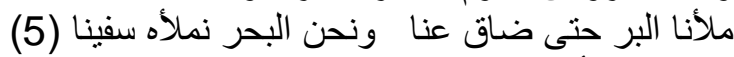

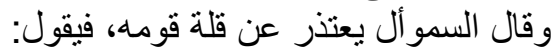

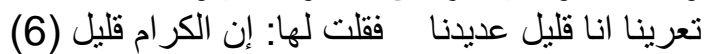
و هذه القلة العددية كثير ا ما تسبب للأقلية ان تلقى الظلم والاضطيل النهاد من الأكثرية، وخصوصا إذا غلب الاكثرية التعصب

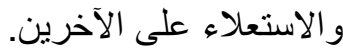
ولهذا نرى الأقليات في الأحاء الارض تلتضامن وتتلاحم فيما بينها، لتحافظ على كيانها أما الاكثرية، وان كانت الأقليات

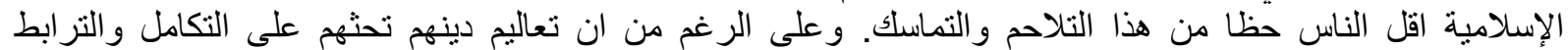
و التعاون فيما بينهم على البر والتقوى لا على الاثم و العدوان بحكم الاخوة الإسلامية الوأصلة بينهم، و العقيدة الإسلامية التي تجعلهم كالجسد الواحد.

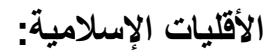

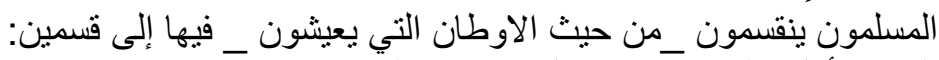

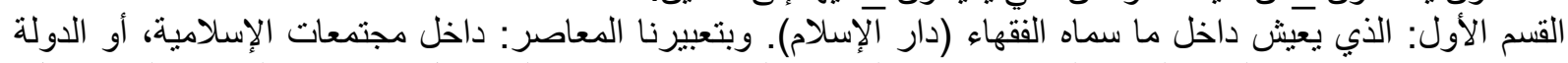

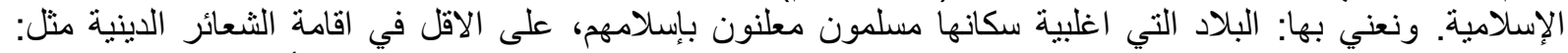

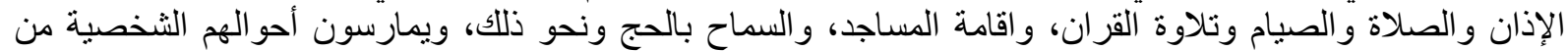
الزواج و الطلاق ونحو ها وفق أحكام دينهم. و القسم الثاني: هو الذي يعيش خارج الذام (دار الإسلام) بعيدا عن المجنمعات الإسلامية أو عن (العالم الإسلامي).

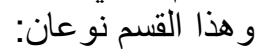
النوع الأول: من الهل البلاد الأصليين، الذين اسلموا من قديم، ولكنهم يعتبرون أقلية بالنسبة لمواطنيهم الاخرين من غير

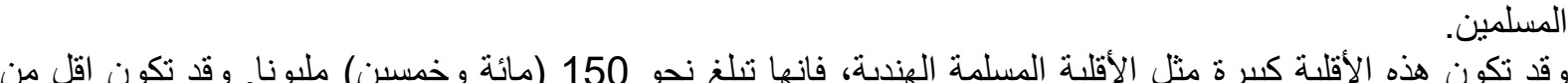

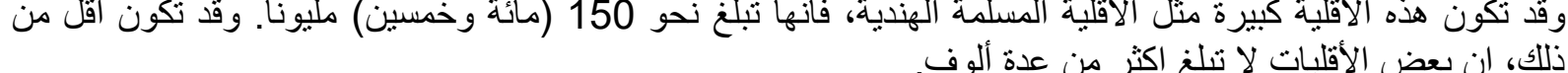

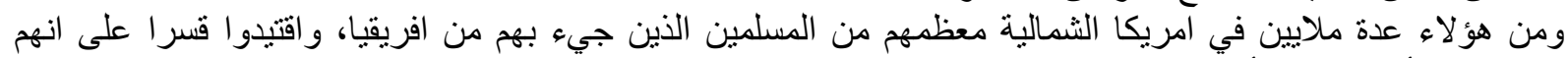
رقيق، وهم أحر وار ابناء أحرار.

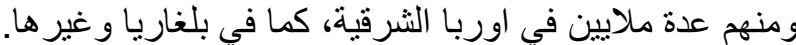

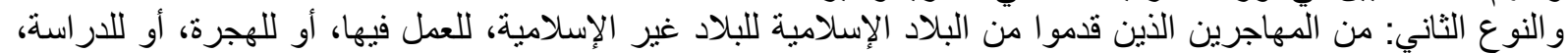

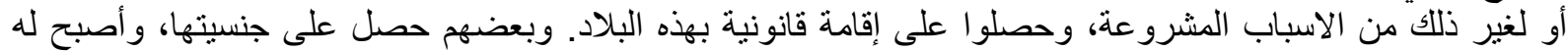

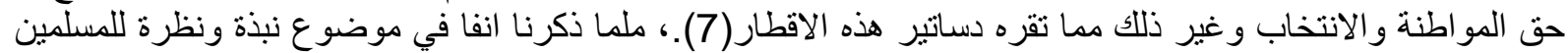
و وكيفية ندماجهم مع الغرب.

المقاصد الإسلامية المقاصد لغة: جمع مقصد، والإمية المقصد مأخوذ من (قصد)، يقال: قصد يقصد قصداً ومقصداً (8)، فالقصد والمقصد بمعنى

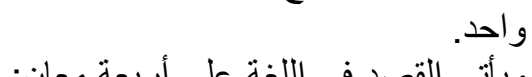
ويأتي القصد في اللغة على أربعة معانٍ:

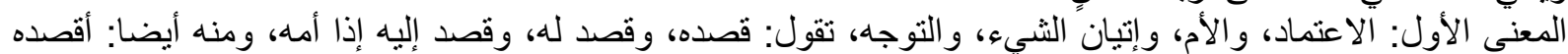

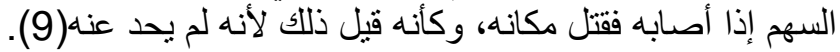

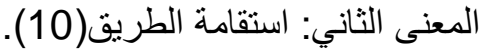

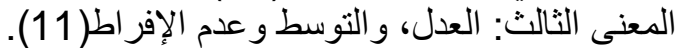

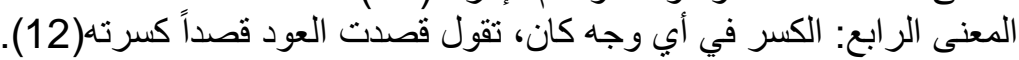




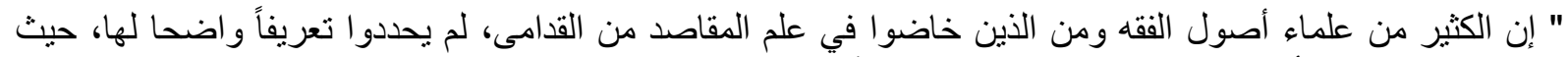

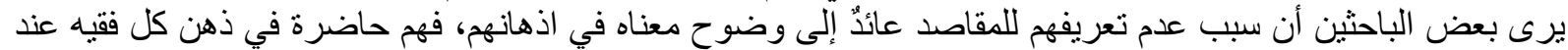

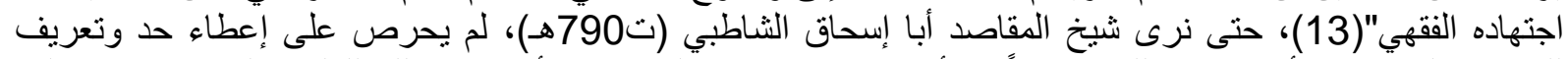

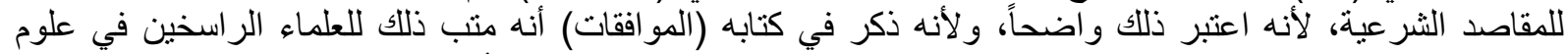

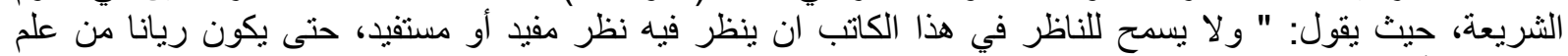

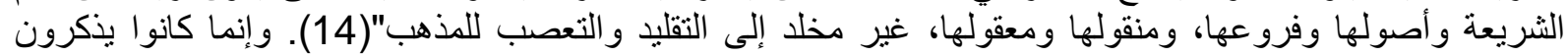

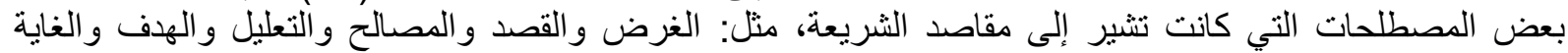

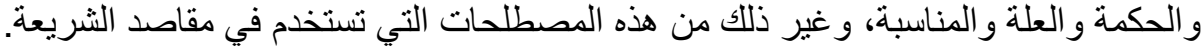

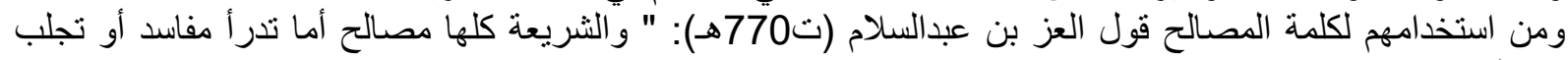

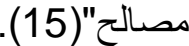
أما العلماء المعاصرة فقد تقاربت رؤيتهم الدالة على المقاصد مع القدامى، فقاموا بتاصيلها وجعلها علما قائما بذاته، منفرداً

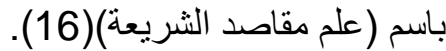

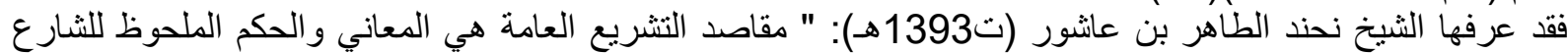

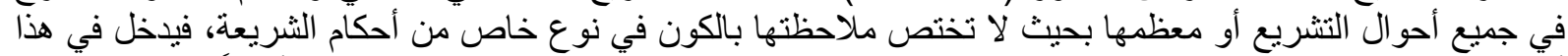

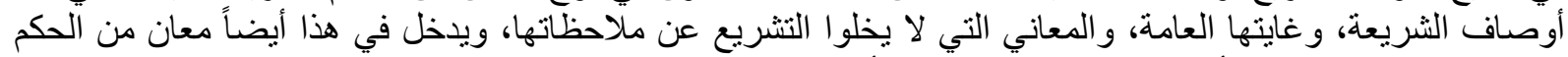

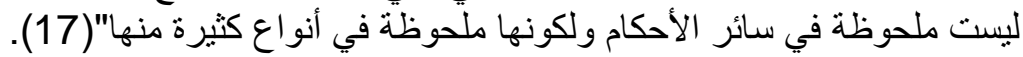

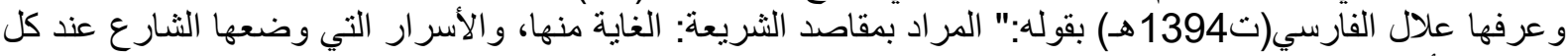

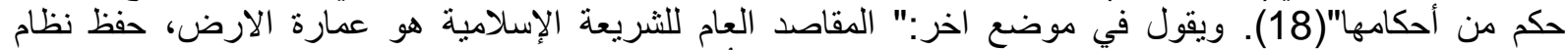

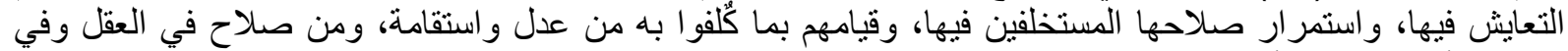

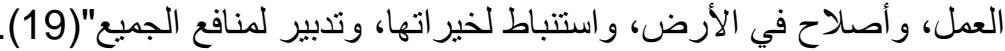

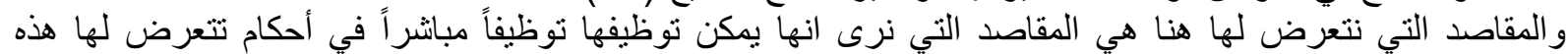

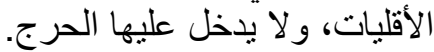

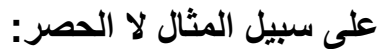
1. 1 نشر الإسلام وحمل الدعوة وتبلاليخها.

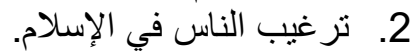

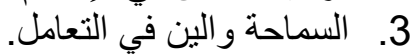

القواعد الفقهية

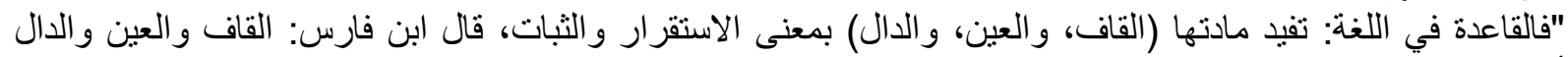

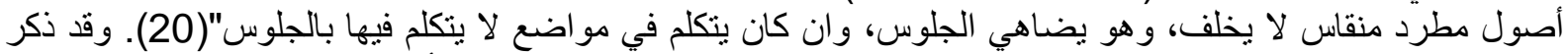

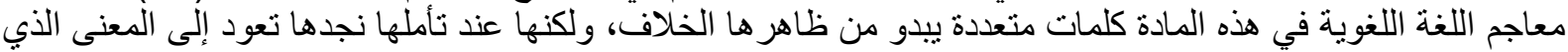

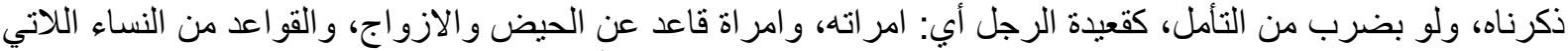

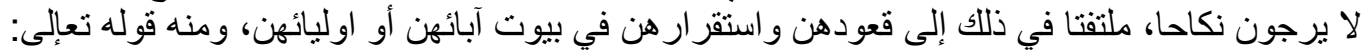

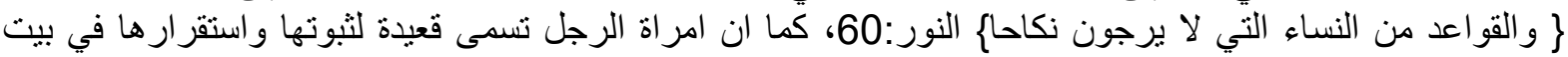

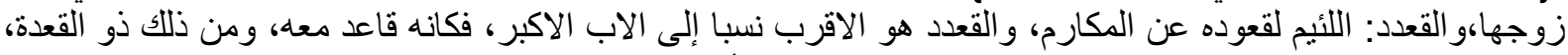

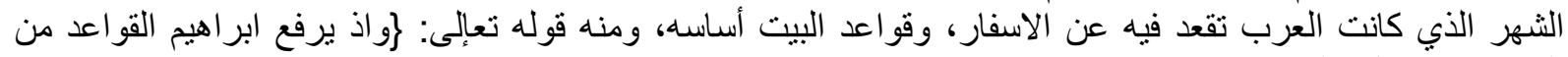
البيت و اسماعيل\{ البقرة: 127.

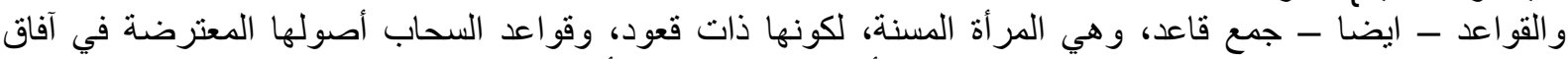

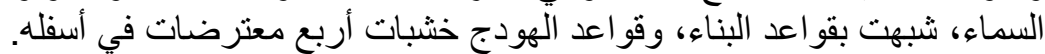

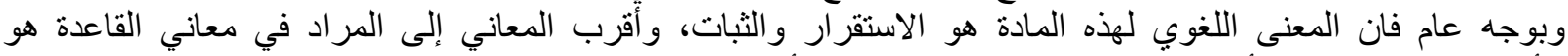

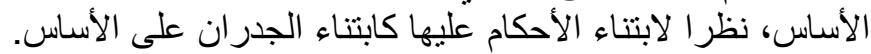

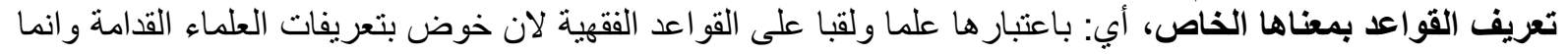

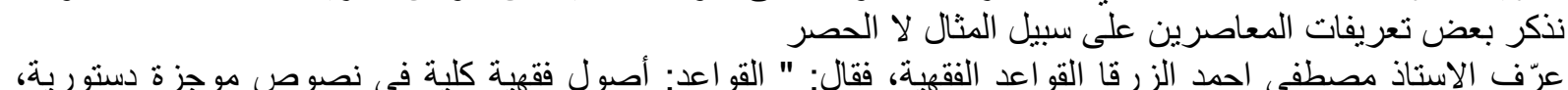
تتضمن أحكاماً تشريعية عامة، في الحوادث التي تدخل تحت موضو عها (21). 
وقال شارح اومبينا: " فهي تمتاز بمزيد من الايجاز في صياغتها على عموم معناها وسعة استيعابها للفروع الجزيئة،

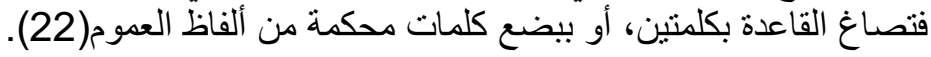

وقد أخذ بهذا التعريف د.محمد مصطفى شلبي، بعد تعديله،وحذفه كلمة دستورية، فقال في تعريفها: " أصول ومبادئ كلية أصواية

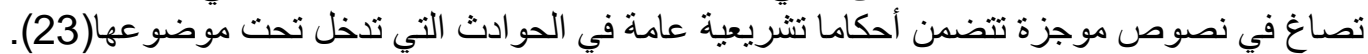
وقد أخذ على هذا التعريف انه عرّف القواعد بمرادفها، وهو فولهية: "أصول فقهية كلية " فتعريفه لفظي وليس علمياً

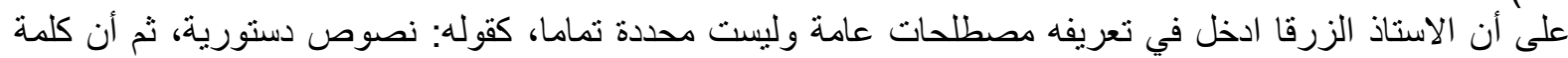

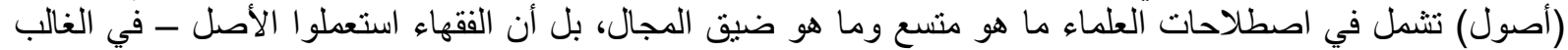

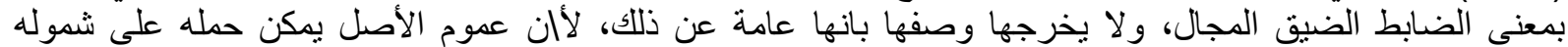

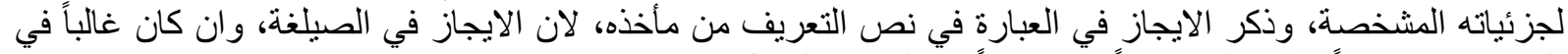

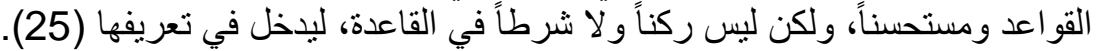
بعض القواعد الفقهية وكيفية توضيفها

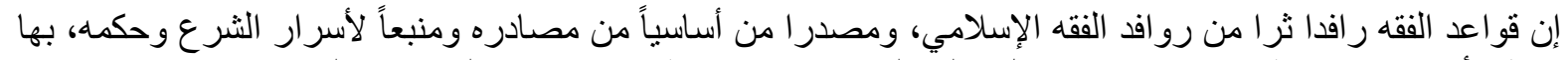

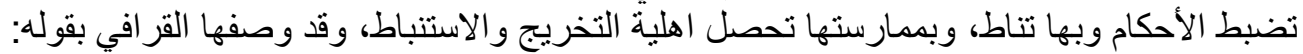

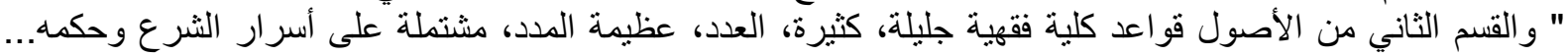

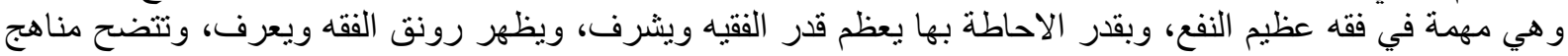
الفتاوى وتكثفف، فيها تنافس العلماء، وتفاضل الفضلاء، وبرز القارح على الجذع، وحاز قصب السابق من فيها

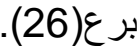

و هي قو اعد كثيرة ومرنة، والاستفادة منها أسهل على الفقيه من الاستفادة من الأصول الهامة، ويمكن نوظيف كثير منها

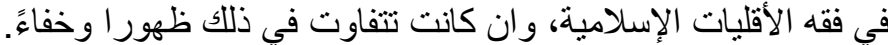

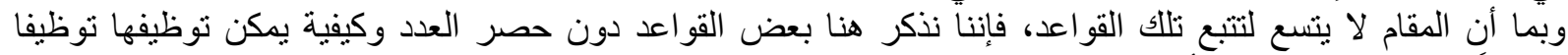

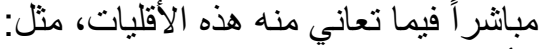
الأمور بمقاصدهاً ما لا يتم الواجب إلا بهاه فهو واجب

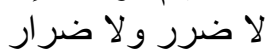
الضرر بدفع بقدر الامكان الضرر يز ال بقدر الامكان الضغان الضرر لا يز ال بضرر مثلك أو كبر منه الطهان

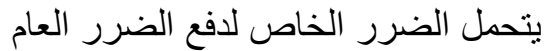
يتحمل الضرر الادنى لدفع الضرر الضر الاعلى الضعى يرتكب اخف الضررين

درء المفسدة اولى من جلب المصلئحة تغتفر المفسدة القليلة لجلب مصلحة كبيرة الفي البحة تفوت ادنى المصلحتين المشقة تجب التيسير

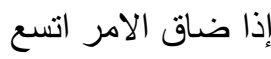

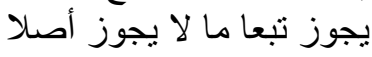
يجوز بقاء وانتهاء ما لا يجوز الإناء النشاء وابتداء الأصل في الاشياء الإباحة الأصل في العاديات و المعاملات النظر إلى العلل و المصالح

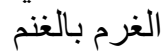
المسلمون عند شروطهر

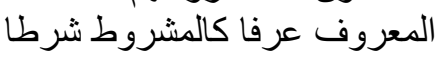
النادر لا حكم لله للاكثر حكم الكل لاله

حقوق الله مبنية على المسامحة. وحقوق العبلى العاد مبنية على المشاحة حقوق الامة مقدمة على حقوق الافر الد اد

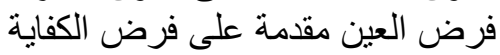




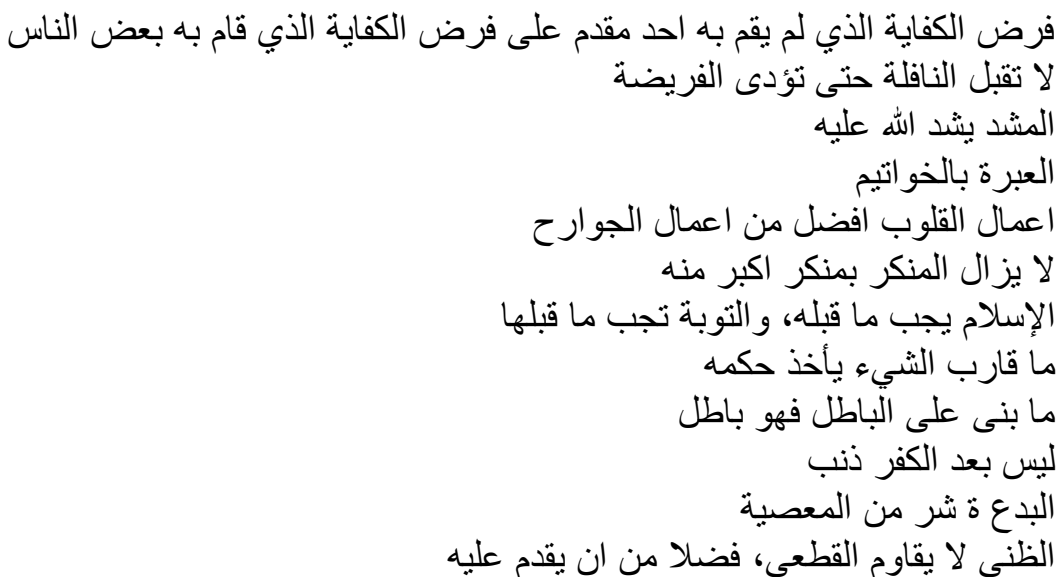

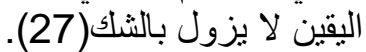

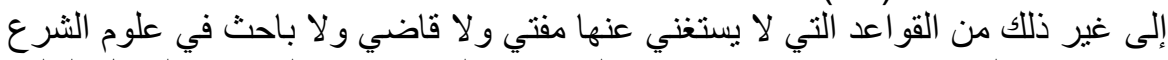

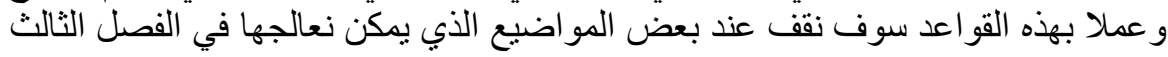

\section{بعض المحور الثالثل في فقه الأقليات الإسلامية وتضن:}

1.نشر الإسلام عن طريق خلق سوق إسلامي أو تجار مسلمين:

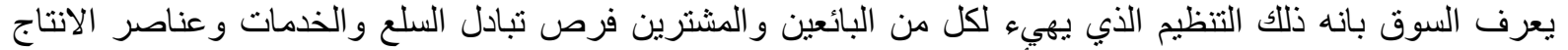

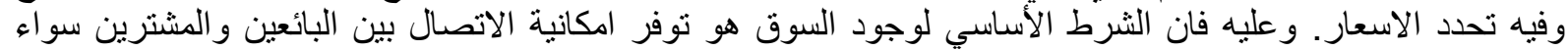

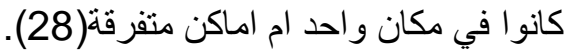
ونحن هنا سوف نركز فئ على تبادل التجاري في مكان واحد لجلب الأنظار من أجل خلق سوق تجاري للأقليات الموجودة في دولة ما. عنى الفقهاء بوضع معايير خاصة للاسواق فذهبوا إلى انه يجب فيها ان تكون رفيعة متسعة وتقوم الدكاكين والمحلات

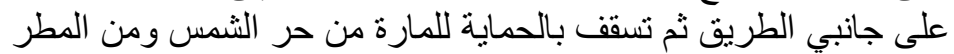
يقول الثيرازي: (ينبغي ان تكون الاسواق في الارتفاع والاتساع على ما وصفته الروم قديما)(29).

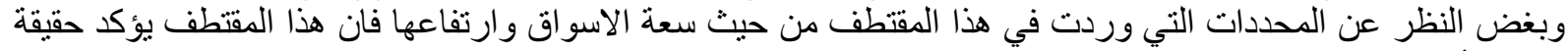

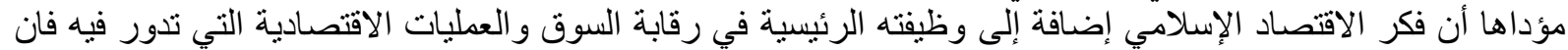

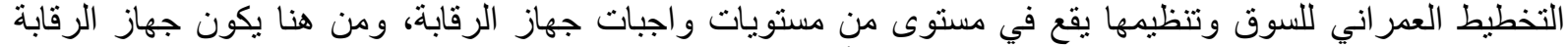

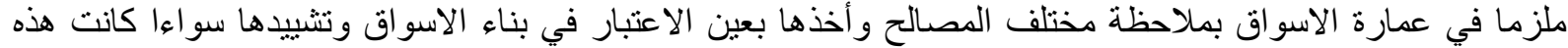

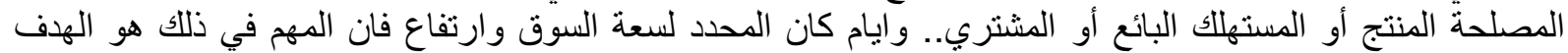
و الغاية من هذه السعة وذللك الارتفاع ومن وجود السوق أصلا في مثل هذه البلدان، وهو ادارة وان العملية الأقتصادية بما يفي

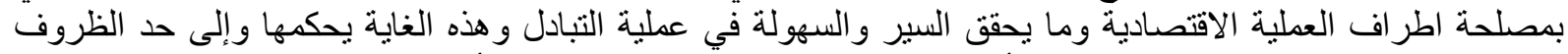

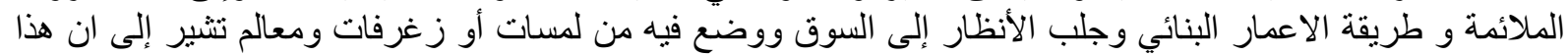

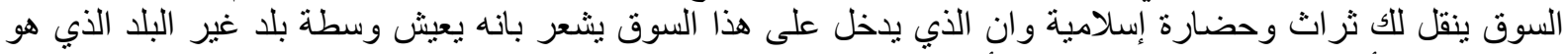

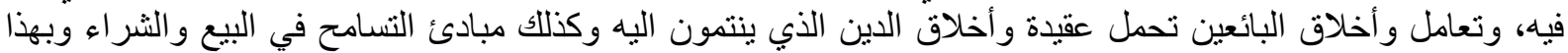

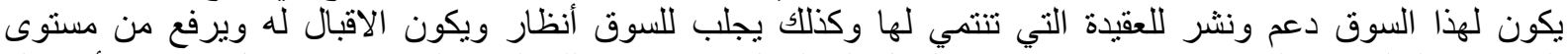
العرض و الطلب في السوق فيرفع من مستوى اللدخل المسلم الذي يقوم في تلك المدن الغريبة مما يجعل اقتصناده أو دخله

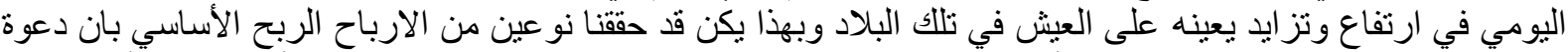

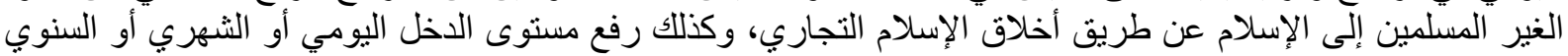

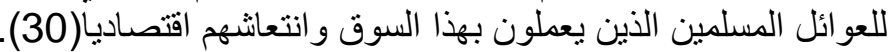

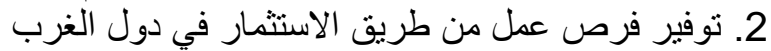

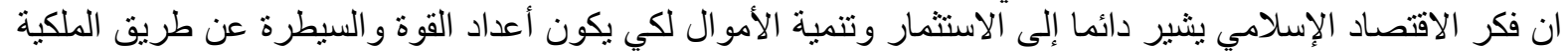

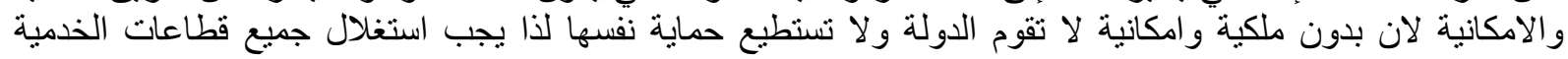




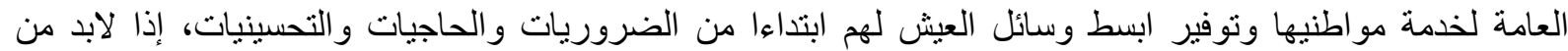

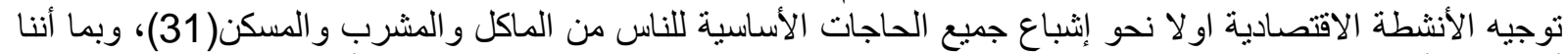

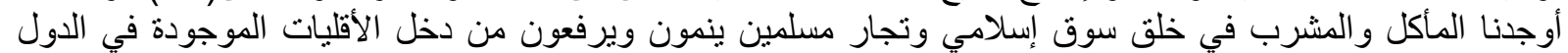

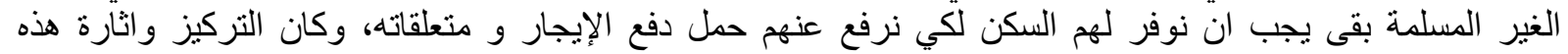

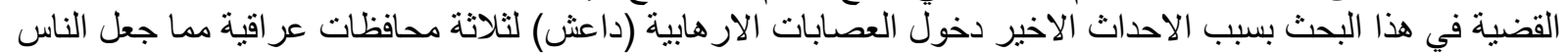

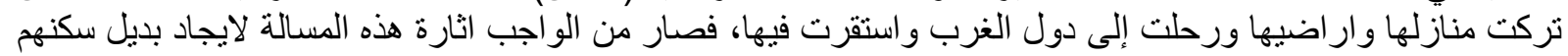

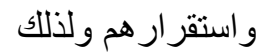

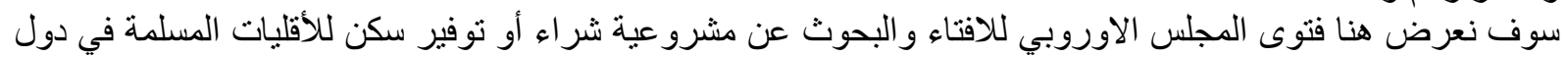
الغرب، و إلى من يريد الوقوف حول اتفاصيل هذه الفتوى و الاطلاع على ار اء الفقهاء بالتفصل بمكنه مر اجعة كتاب الثيخ

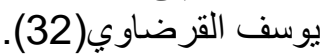
2- فتوى المجلس الأوربي للافتاء والبحوث:

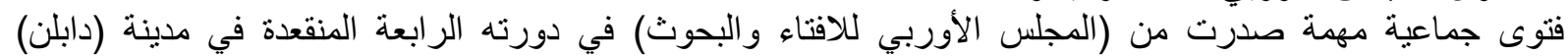
بجمهورية ايرلندا في شهر دجب

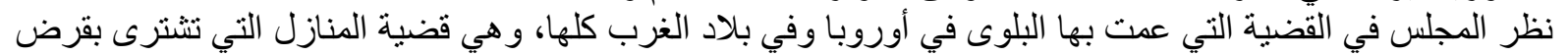
ربوي بو اسطة البنوك التقليدية.

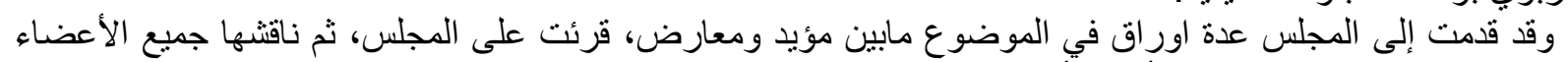

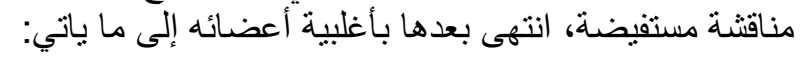

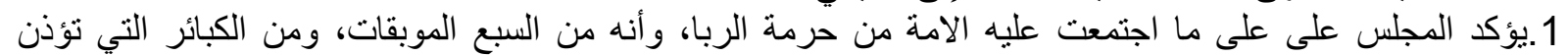

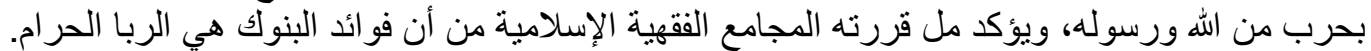

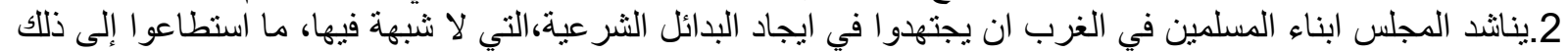

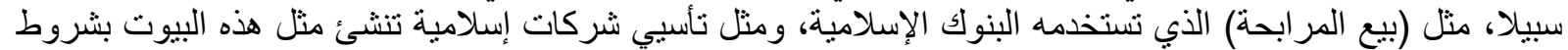

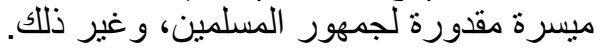

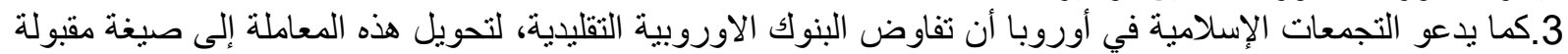

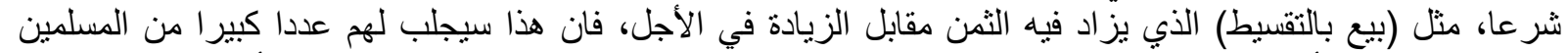

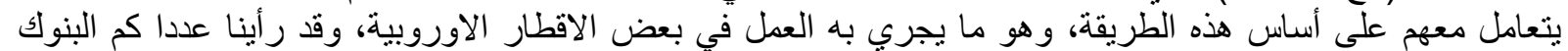

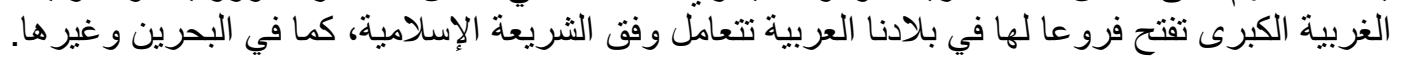

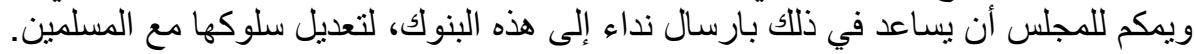

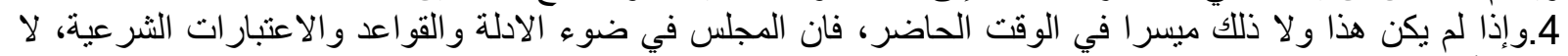

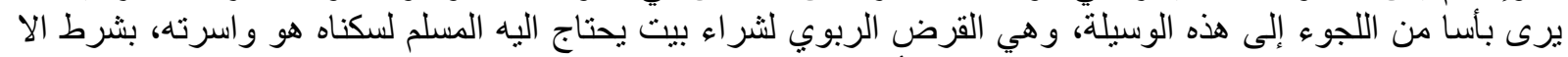

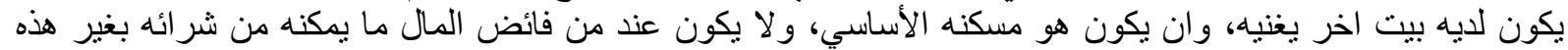
الوسيلة، وقد اعتمد المجلس في فتواه بلى بلى مرنكزين أساسيين:

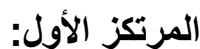

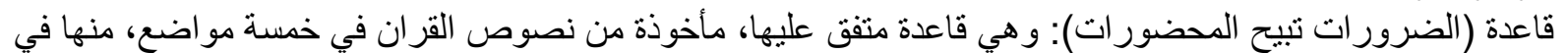

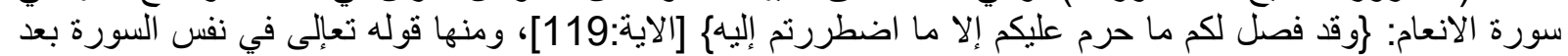

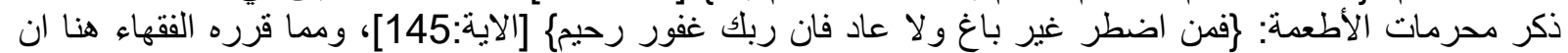

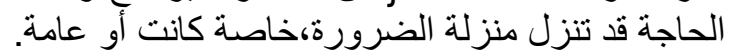

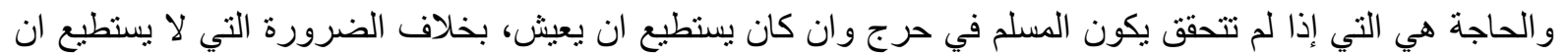

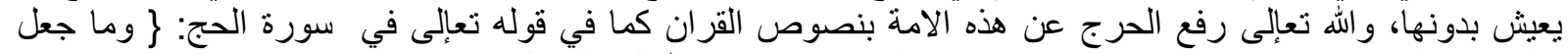

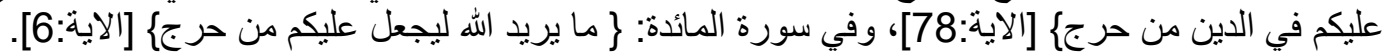

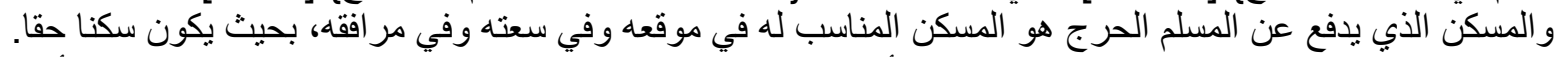

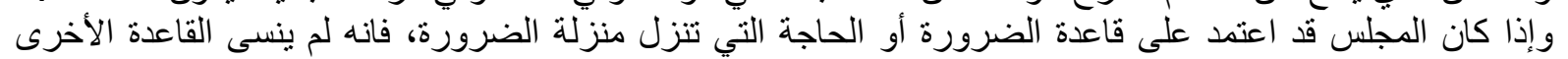

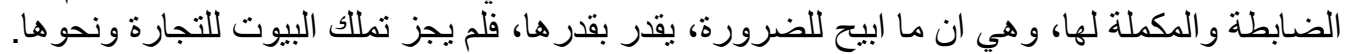

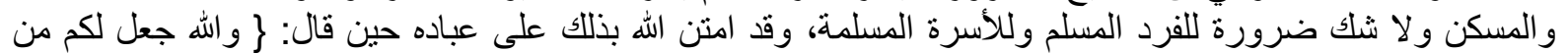

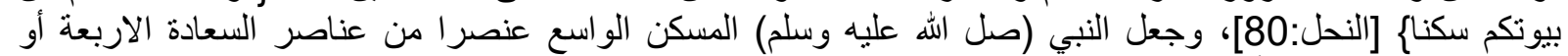

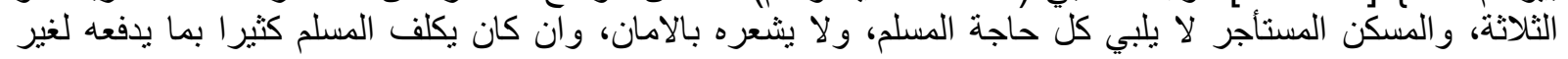

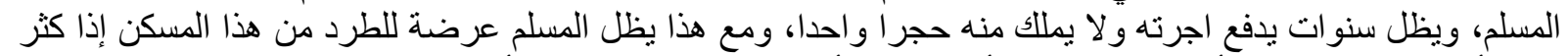

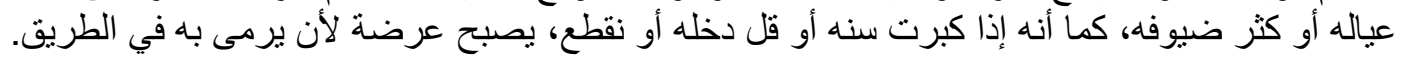


وتملك السكن يكفي المسلم هذا الهم، كما انه يمكنه ان يختار المسكن قريبا من المسجد والمركز الإسلامي، والدمرسة

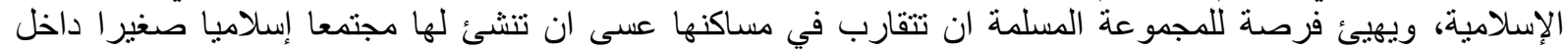

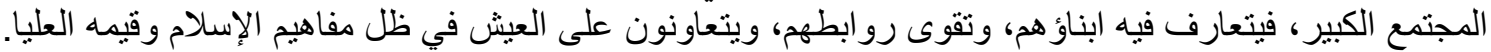

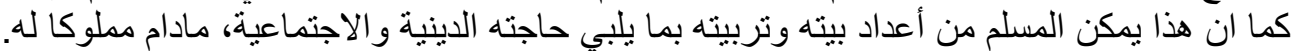

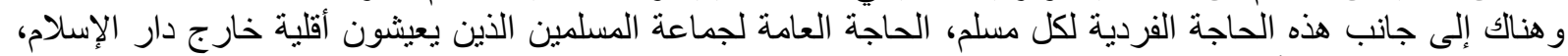

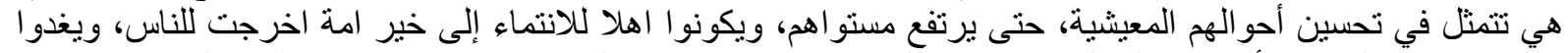

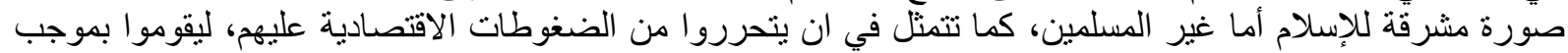

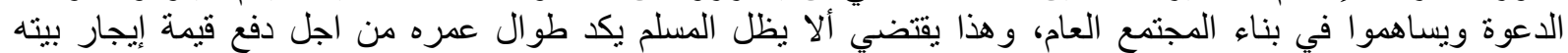

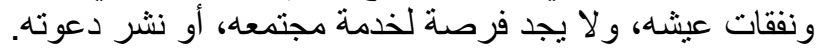

المرتكز الثاني: (وهو مكمل للمرتكز الأول الأساسي)

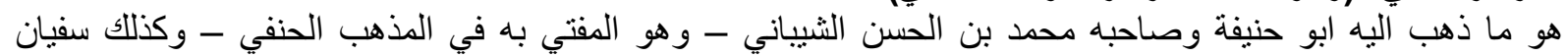

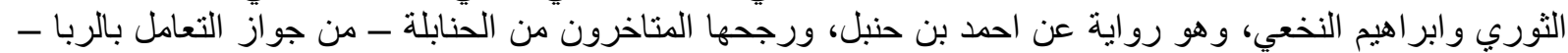

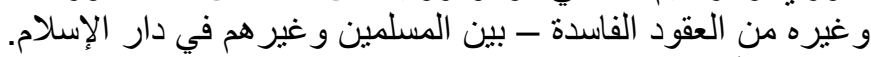
ويرجح الأخذ بهذا المذهب هنا الفنان عدة اعتبار ات، منها:

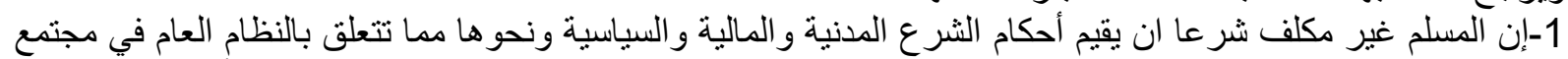

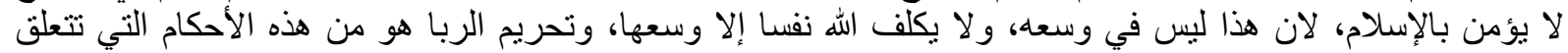

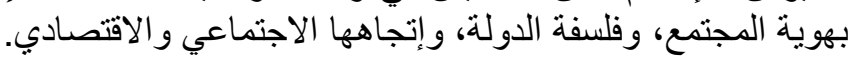

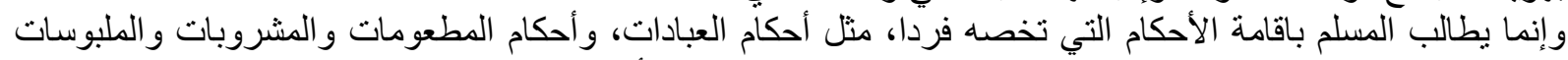

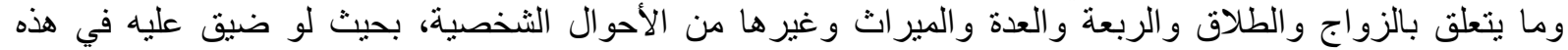

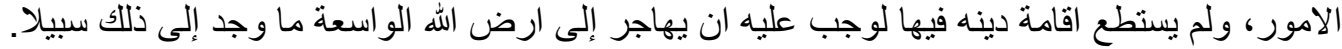

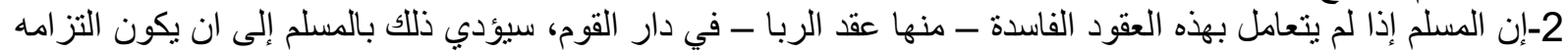

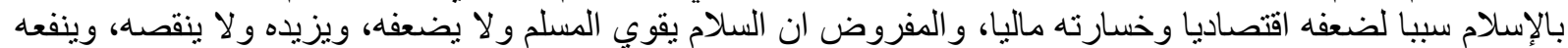

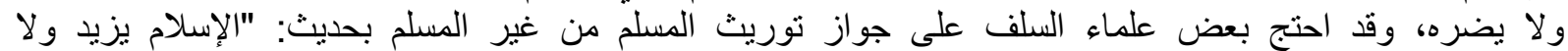

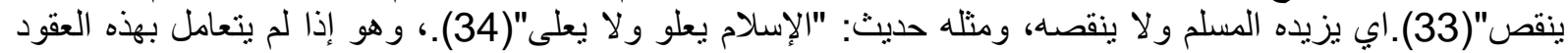

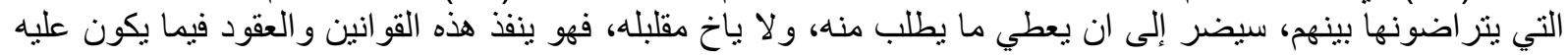

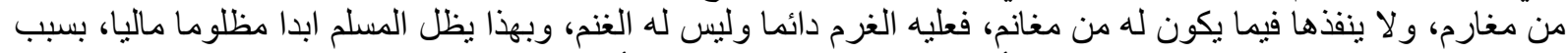

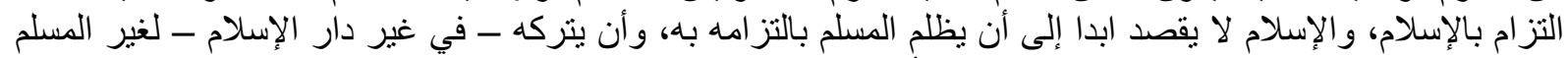

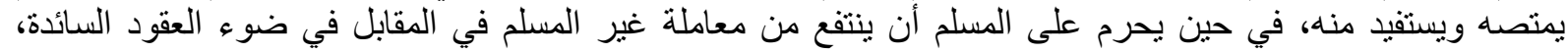

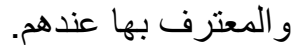
وما يقال من مذهب الحنفية انما يجيز التعامل بالربا في حالة الأخذ لا الإعطاء،لأنه لا فائدة للمسلم في الإعطاء ' وهم لا يجيزون التعامل بالعقود الفاسدة إلا بشرطين: الأول: أن يكون فيها منفعة للمسلمين.

الثاني: ألا يكون فيها غدر و لا خيانة لغيان لغير المسلم، وهنا لم تتحقق المنفعة للمسلم.

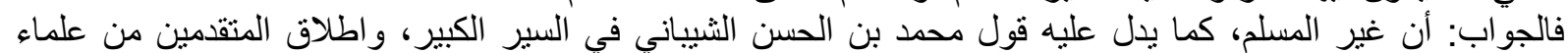

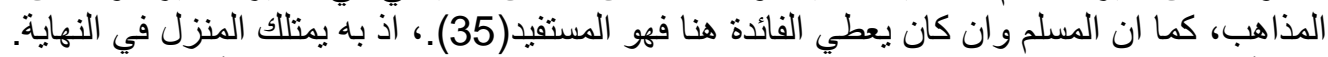

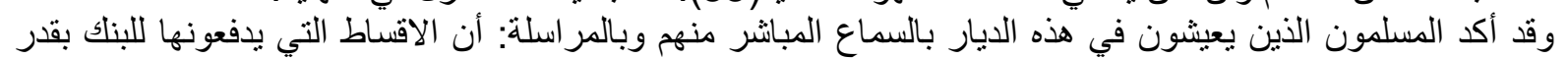

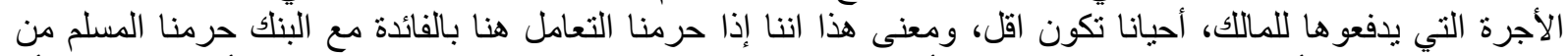

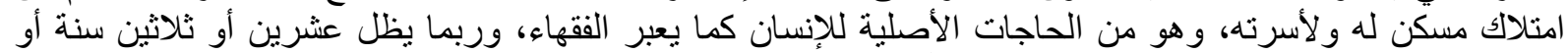

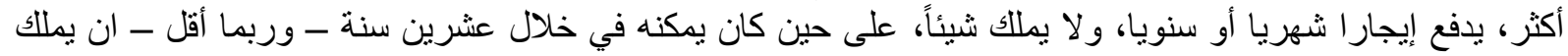

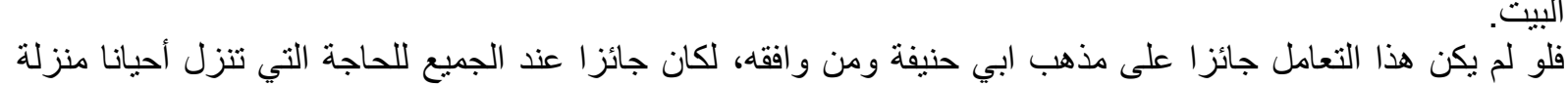

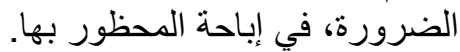

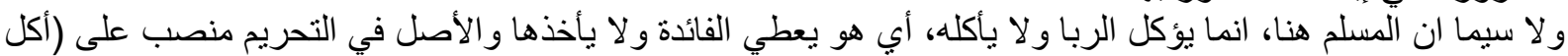

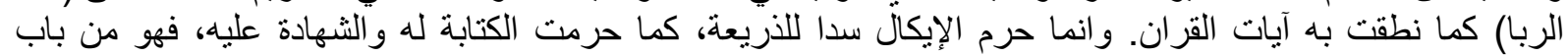
تحريم الوسائل لا تحريم المقاصد. 
ومن المعلوم أن أكل الربا المحرم لا يجوز بحال، أما إيكاله - بمعنى 'طاء الفائدة - فيجوز للحاجة، وقد نص على ذلى ذلك

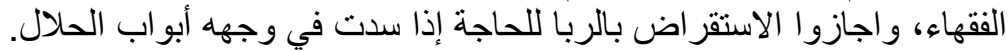

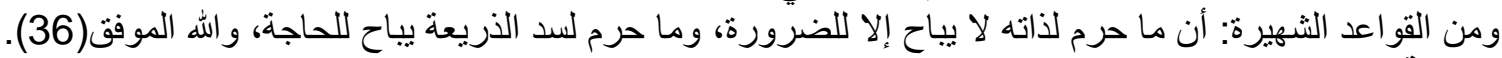

الخاتمة وفي الختام جاء حصادنا التالي:

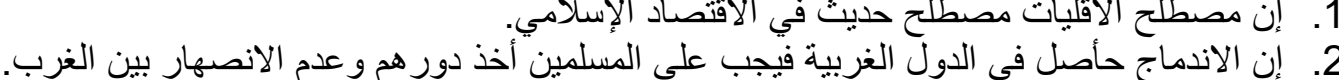

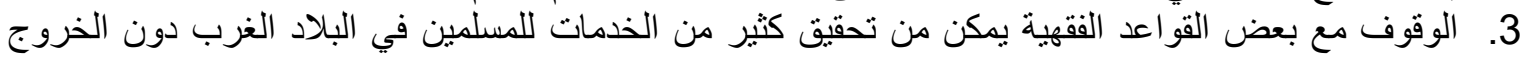
عن اطار السلام.

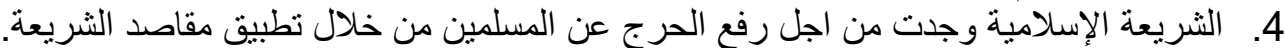

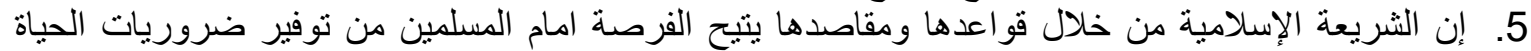

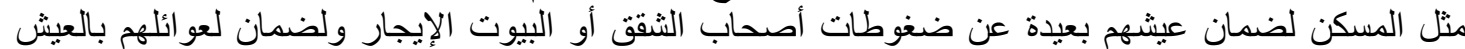
الرغيد. 6. المجمع الفقهي الأوربي يواكب العصر ويتدارك المعاملات المعاصرة بفتاوى يعين المسلم على التعامل مع هذه المعاملات وفق حدود مشرو عة. المئ.

$$
\text { ثبت المصادر والمراجع }
$$

ابر اهيم بن موسى بن محمد الثاطبي الغرناطي ابو اسجاق / الموافقات /تحقيق مشور آل سلمان، دار ابن عفان بالخبر، ط1. ابو الحسن علي بن عمر بن احمد بن مهدي بن دينار البغدادي الدار القطني / سنن الدار القطني / تحقيق: شعيب ارناؤوط،

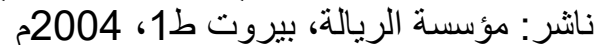

ابو عبداله الحاكم محمد بن عبدالله بن محمد بن حمدوي / المستدر على الصحيحين / تحقيق: مصطفى عبدالقادر عطا، دار

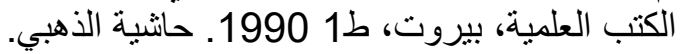

أبي عبداله الزوزني، كتاب شرح المعلقات السبع، لجنة التحقيق في الدئية الدار العالمية.

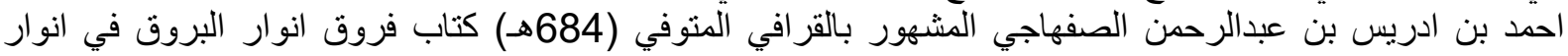

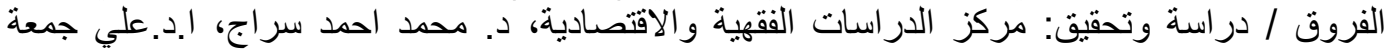

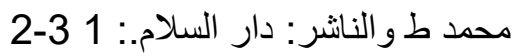
احمد بن الحسين بن علي بن موسى الخرساني المعروف بـ البي بكر البيهقي / سنن الكبرى / تحقيق: محمد عبدالقادر

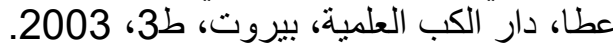

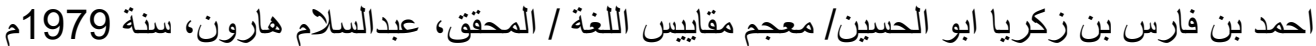

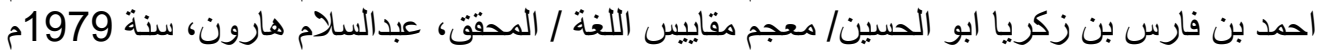

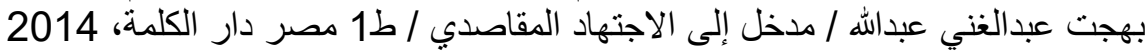

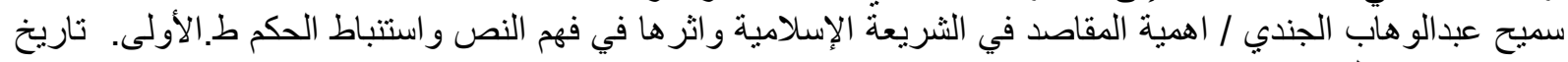
النشر: 2012: 26

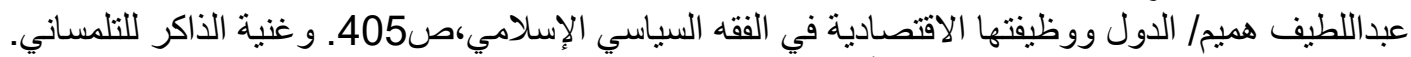

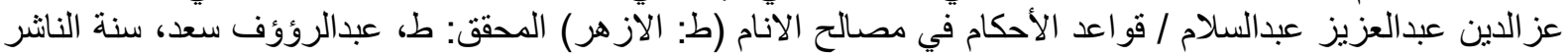
1991

علال الفارسي / مقاصد الثريعة الإسلامية ومكارمها، (ت:1991)هـ)، دار الغرب الإسلامي بيروت، الطبعة الخامسة

فتوى الثيخ مصطفى الزرقا، وتفسيره لمذهب الحنفية

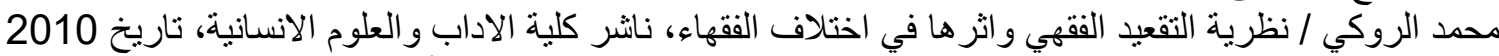

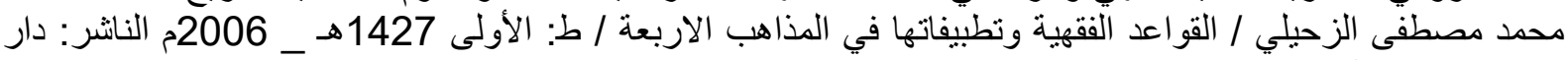

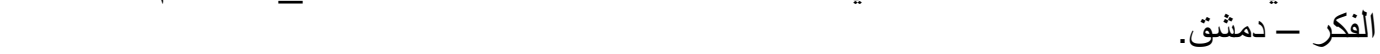
محمد مصطفى شلبي/ المدخل في التعريف بالفقه الإسلامي وقو اعد الملكية والعقود فيه / نانشر: دار النهضة العربية

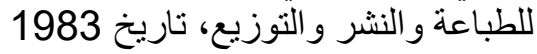
مدخل للفكر الاقتصاد في الإسلام. د.سعيد سعد مرطان، الطبعة الثانية، سنة دالنة 2004م، مؤسسة الرسالة. 


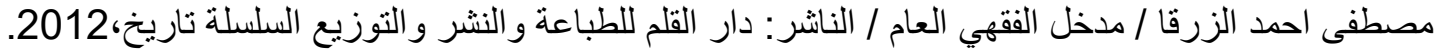

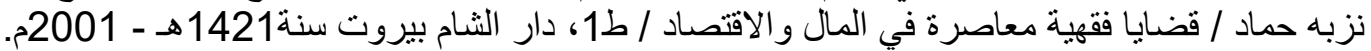

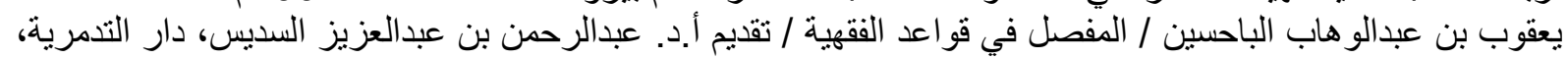

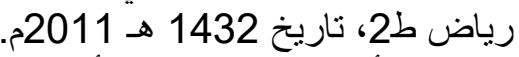

يوسف القرضاوي/ فقه الأقليات المسلمة/ ط: الأولى دار الثروق، سنة 1422هـ - 2001م.

المقالاث

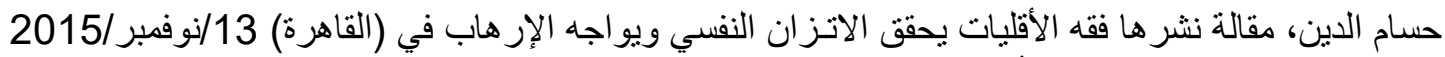

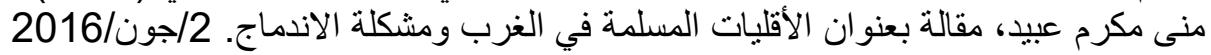

\section{الهوامش}

(1) انظر: حسام الدين، مقالة نثر ها فقه الأقليات يحقق الاتز ان النفسي ويواجه الإرهاب في (القاهرة) 13/نوفمبر/2015

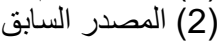

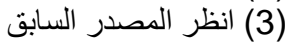

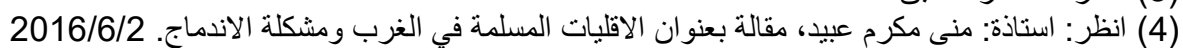

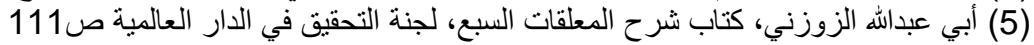

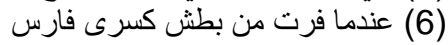

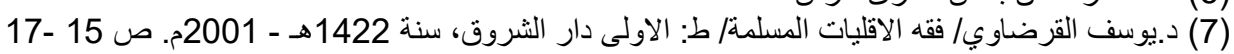

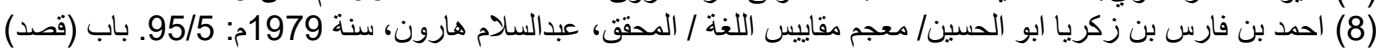

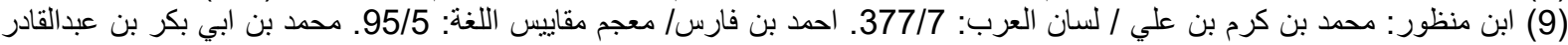

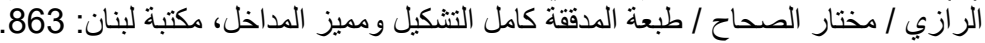

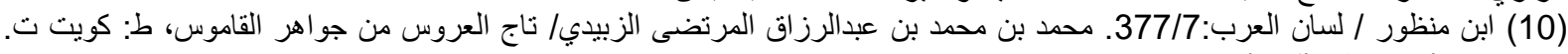

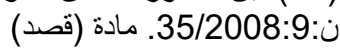

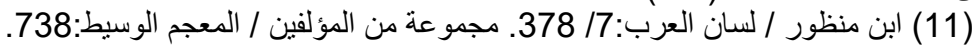

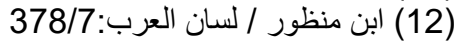

(13) سميح عبدالو هاب الجندي / الهية المقاصد في الثريعة الاسلامية واثر ها في فهم النص واستنباط الحكم ط.الاولى. تاريخ النشر: 2012:

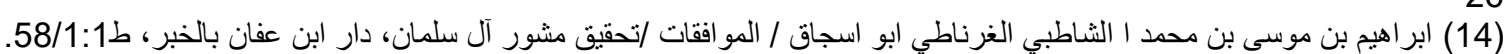

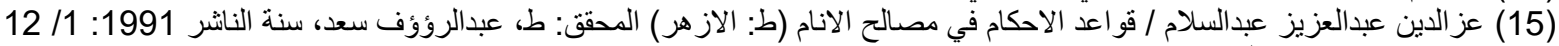

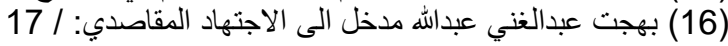

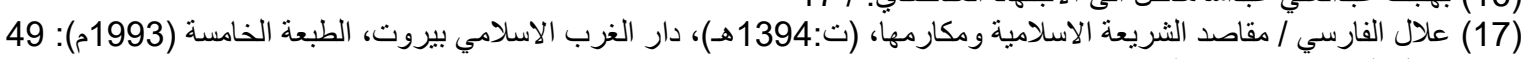

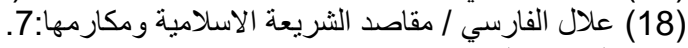

(19) المصدر السابق: 45- 46 (18)

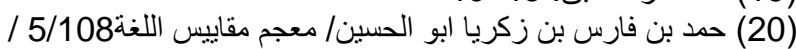

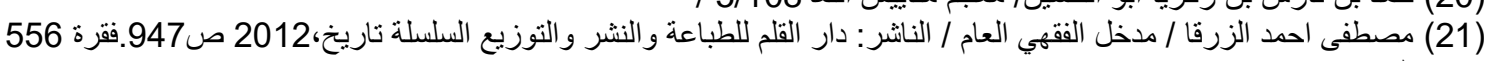

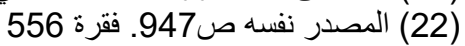

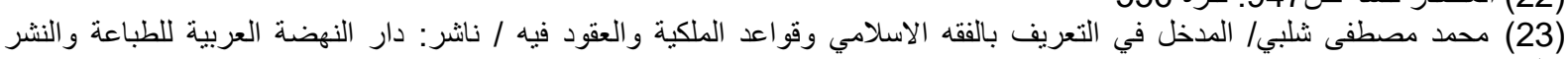
و التوزيع، تاريخ 1983. 19: صن 324

(24) محمد الروكي / نظرية التقعيد الفقهي و اثر ها في اختلاف الفقهاء، ناشر كلية الاداب و العلوم الانسانية، تاريخ 2010.

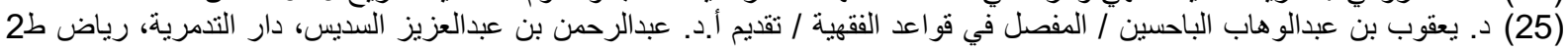

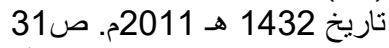

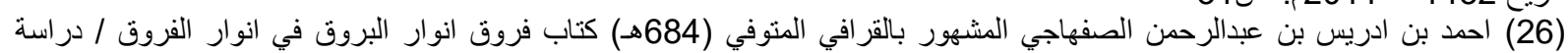

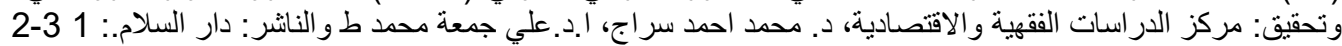

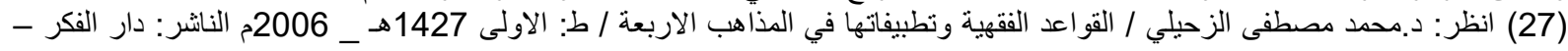

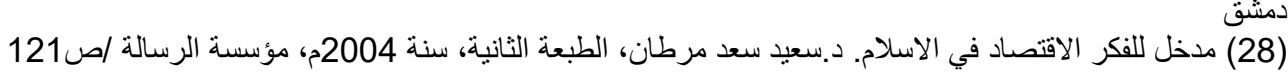

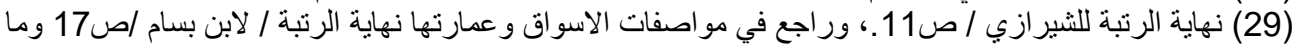

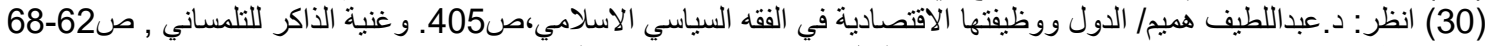

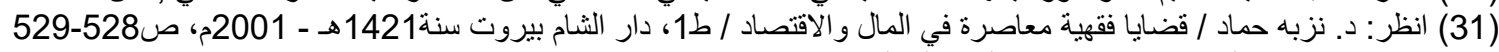

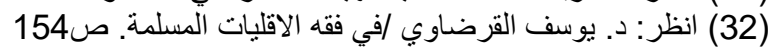




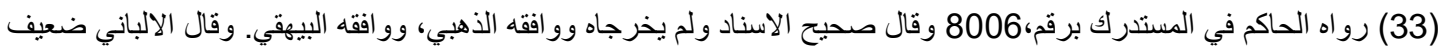

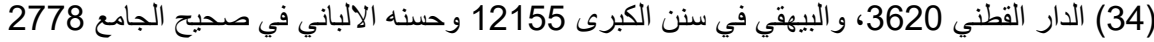

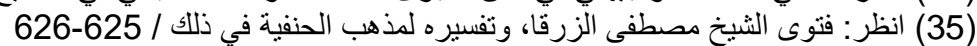

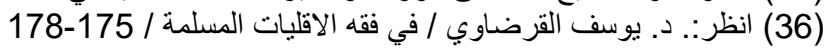

